\title{
Drug Induced Hybrid Electrospun PLA:Cell Derived Extracellular Matrix Scaffolds Support the Survival and Function of Human Primary Hepatocytes
}

\section{Rhiannon Grant}

University of Edinburgh

John Hallett

University of Edinburgh

Stuart Forbes

University of Edinburgh

David Hay

University of Edinburgh

Anthony Callanan ( $\nabla$ anthony.callanan@ed.ac.uk)

University of Edinburgh

\section{Research Article}

Keywords: PHHs, ECM, SEM, hepatocytes

Posted Date: November 30th, 2020

DOI: https://doi.org/10.21203/rs.3.rs-110396/v1

License: (c) (i) This work is licensed under a Creative Commons Attribution 4.0 International License.

Read Full License 
Drug induced hybrid electrospun PLA:cell derived extracellular matrix scaffolds support the survival and function of human primary hepatocytes

Dr Rhiannon Grant ${ }^{1}$, Mr John Hallett ${ }^{2}$, Prof Stuart Forbes ${ }^{2}$, Prof David Hay ${ }^{2}$, Dr Anthony Callanan ${ }^{1 *}$

1. Institute for Bioengineering, School of Engineering, University of Edinburgh, Scotland, UK

2. Scottish Centre for Regenerative Medicine, University of Edinburgh, Scotland, UK Corresponding author: anthony.callanan@ed.ac.uk

Data sharing: All data generated or analysed during this study are included in this published article. 


\section{Abstract}

An exponential increase in liver disease is driving a critical shortage of donor livers for patient transplant. In the UK alone, 58 people died in 2019 while waiting for a donor organ. A solution is sought in the form of tissue-engineered devices which support the survival and function of primary human hepatocytes. Previous work has shown that biofunctionalization of electrospun scaffolds influences hepatocytes. This study assesses the impact of drug-derived ECM on primary human hepatocytes (PHHs); a gold standard research resource.

Hepatocytes seeded onto electrospun PLA scaffolds were subjected to drug treatment using histone deacetylase inhibitors. These cells were stripped from the scaffolds to leave behind their ECM. The resulting ECM-PLA scaffolds were seeded with PHHs and cultured for 24/72/120 hours. Scanning electron microscopy (SEM), mechanical and biochemical quantification, histology, and gene expression analyses were performed on the scaffolds.

Results demonstrate PHHs are significantly influenced by the drug derived ECM:PLA scaffolds, with alterations in albumin production and gene expression demonstrated.

Creating multidimensional scaffolds like these provides a method of creating tailored environments for liver bioengineering and the investigation of cell matrix interactions and is a step on the path to providing lab grown organoids for patient transplant. 


\section{Introduction}

Liver disease remains the only increasing cause of premature death in the Western world. The only curative clinical option for advanced liver disease is an organ transplant ${ }^{1,2}$. This exponential increase in incidence is fuelling a critical shortage of donor livers, leading to a high mortality rate and increasing treatment and subsequent financial burdens on the healthcare system. In the UK in 2019, 432 people were still waiting for a donor liver, an increase of $20 \%$ from $2018^{3}$.

Tissue engineers aim to address this shortage by manufacturing alternatives to whole organ transplants ${ }^{1,4-6}$; engineering novel environments which provide vital signals and support for hepatocytes and allow the study of new pharmaceuticals and potential for transplantable devices ${ }^{7,8}$. These environments would ideally incorporate the complex biological and physical signals provided by the in vivo liver and encompass fluid dynamics ${ }^{9,10}$, molecular biology ${ }^{11,12}$, polymer chemistry ${ }^{13-15}$ and cell biology ${ }^{12,16,17}$ to create a liver-like device which could be used to support researchers and clinicians in treating liver disease patients.

One of the major obstacles within the liver tissue engineering field is recapitulating the extracellular matrix [ECM]. The ECM is a dynamic, organ specific collection of proteins, cytokines and other small molecules which provides physical support, mediation of cell:cell communication and modulation of cell behaviour ${ }^{18-20}$. Various studies have demonstrated the influence of altered ECM on the behaviour of hepatocytes in culture; including that of diseased $\mathrm{ECM}^{21,22}$, of synthetically derived $\mathrm{ECM}^{20,23}$ and of individual ECM components ${ }^{24,25}$ on the behaviour of hepatocytes.

Strategies to mimic the in vivo ECM include decellularization of organs, use of recombinant and purified proteins and synthetic scaffolds such as hydrogels and electrospun polymers ${ }^{26-29}$. While these bodies of work provide promising advances in the field; to date no environment has been manufactured which allows hepatocytes to function as they do in vivo or provides a viable, clinically translatable alternative to whole organ transplant ${ }^{30}$. Equally, primary human hepatocytes are generally considered the gold standard for studying hepatocyte biology, however, they are a rare resource and as such are under-represented in the liver tissue engineering research field ${ }^{31}$.

Increasingly, researchers recognise the value of cell derived ECM; harnessing cells as a factory to produce ECM environments for cells ${ }^{32}$. Drug-induced hybrid electrospun poly-capro-lactone:cellderived ECM scaffolds for liver tissue engineering have shown previous success ${ }^{23}$. These scaffolds were manufactured using a sacrificial, ECM-producing cell layer which was seeded onto a novel electrospun scaffold and then treated with histone deacetylase inhibitors (iHDACs) ${ }^{33-36}$ to biofunctionalize the scaffold with ECM components. The initial cell layer was removed with a detergent-based decellularization method, and the resulting hybrid polymer-ECM scaffolds seeded with HepG2s for validation. Drug-induced hybrid polymer-ECM scaffolds had a significant positive influence on the gene expression profile, attachment, and survival of liver cells. These scaffolds represent a unique method of inducing and altering the production of ECM and of exerting an influence on phenotypic behaviour of cells, as well as future potential as an implantable treatment platform for liver disease patients. However, these scaffolds ECM layer was produced by a bladder epithelial cell line and validated using a HepG2 cell line limiting their current translatability. Use of gold standard primary human hepatocytes and liver-relevant ECM would highlight the benefits and full potential of this platform approach for liver disease patients.

With this background in mind we manufactured the next generation of drug-induced hybrid electrospun scaffolds; using poly-lactic-acid as a biocompatible and biodegradable polymer for the scaffolds and using sodium butyrate and valproic acid as previously described to alter the ECM biodecoration by a sacrificial liver cell line; THLE-3s. These scaffolds were decellularized and stored until primary human hepatocyte cells, obtained from a donated cadaveric liver, were available (Figure 1). Results demonstrate that the ECM on the scaffolds is drastically altered by the drug treatment; displaying different mechanical and biochemical properties. Albumin production, cell survival and gene expression of the primary hepatocytes were all altered in response to the hybrid drug induced ECM:PLA scaffolds. This work demonstrates the translatability of the hybrid protein:polymer scaffolds 
and further elucidates the impact of differing ECM profiles on the behaviour of primary human hepatocytes.

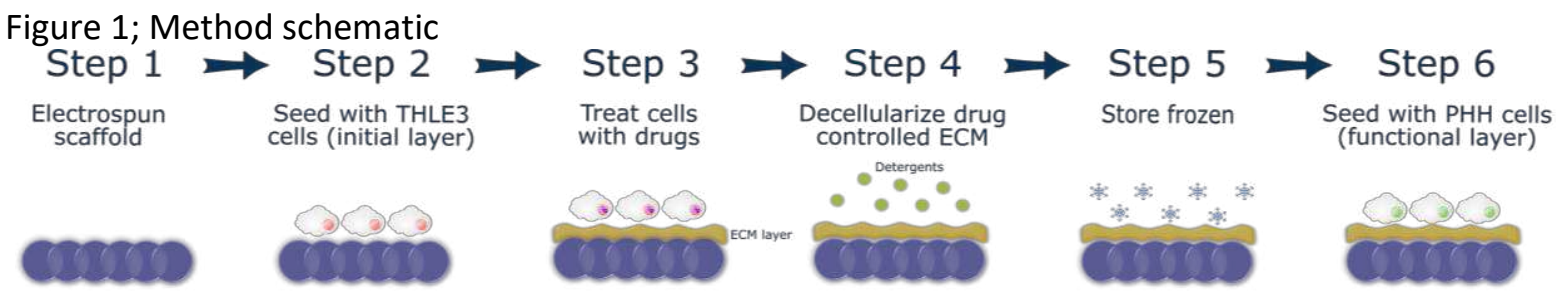

\section{Results}

\section{Mechanical profiling of scaffolds}

The Young's modulus at 0-40\% strain analysis by one-way ANOVA and Games-Howell post hoc analysis $(n=3, p=<0.05)$ showed a significant difference between V-ECM scaffolds and all other conditions (Table 1); indicating that the use of valproic acid to alter ECM production has significantly altered the mechanical qualities and structure of the ECM and resulting in a stiffer environment for scaffolds. NDECM and NaB-ECM both exhibit lower Young's modulus than both PO and V-ECM scaffolds, indicating that a 'normal', non-drug derived ECM and a NaB derived ECM are less stiff than a scaffold with no $E C M$ 'PO', as would be expected from a hydrated, protein-based ECM in comparison to an electrospun polymer mat.

Table 1; Young's modulus (MPa) of each scaffold.

\begin{tabular}{|c|c|c|c|c|}
\hline Strain & Polymer only & No drug treatment & Valproic acid & Sodium butyrate \\
\hline $\mathbf{0 - 1 0 \%}$ & $0.00021 \pm 0.00009$ & $0.00011 \pm 0.00007$ & $0.00042 \pm 0.00049$ & $0.00017 \pm 0.00005$ \\
\hline $\mathbf{1 0 - 2 0 \%}$ & $0.00020 \pm 0.00009$ & $0.00021 \pm 0.00009$ & $0.01543 \pm 0.01639$ & $0.00016 \pm 0.00006$ \\
\hline $\mathbf{2 0 - 3 0 \%}$ & $0.00050 \pm 0.00049$ & $0.00024 \pm 0.00015$ & $0.07181 \pm 0.06190$ & $0.00023 \pm 0.00011$ \\
\hline $\mathbf{3 0 - 4 0 \%}$ & $0.00724 \pm 0.00994$ & $0.00177 \pm 0.00160$ & $0.46913 \pm 0.43570$ & $0.00028 \pm 0.00016$ \\
\hline
\end{tabular}

\section{Scanning electron microscopy}

Scanning electron microscopy reveals visibly altered ECM in each condition (Fig 2).

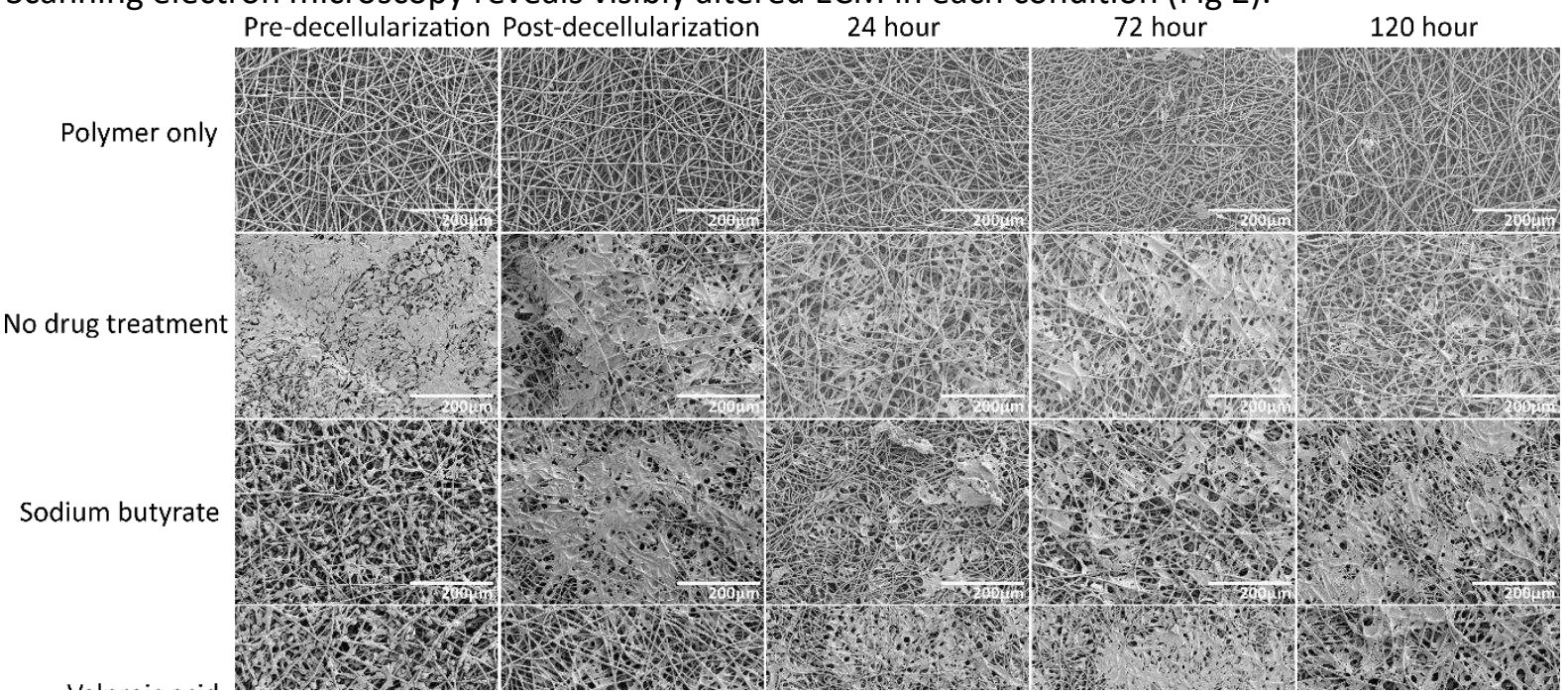

Figure 2; SEM of Scaffold-ECM constructs and functional cell layers

Scanning electron microscopy images of the decellularized scaffold-ECM constructs and functional cell layers at 24, 72 and 120 hours culture. Topographical differences are clearly evident on decellularized constructs. 500x magnification. 
This phenomenon was also observed in the previous study; with each drug exerting a different effect on the visual appearance of the $\mathrm{ECM}^{23}$. Equally, SEM imaging demonstrates a confluent initial cell layer and complete decellularization of the initial cell layer of THLE-3s. Decellularization was confirmed by use of Picogreen DNA analysis (Fig 3). Primary human hepatocytes are evident on the scaffolds at 24, 72 and 120 hours on each scaffold.

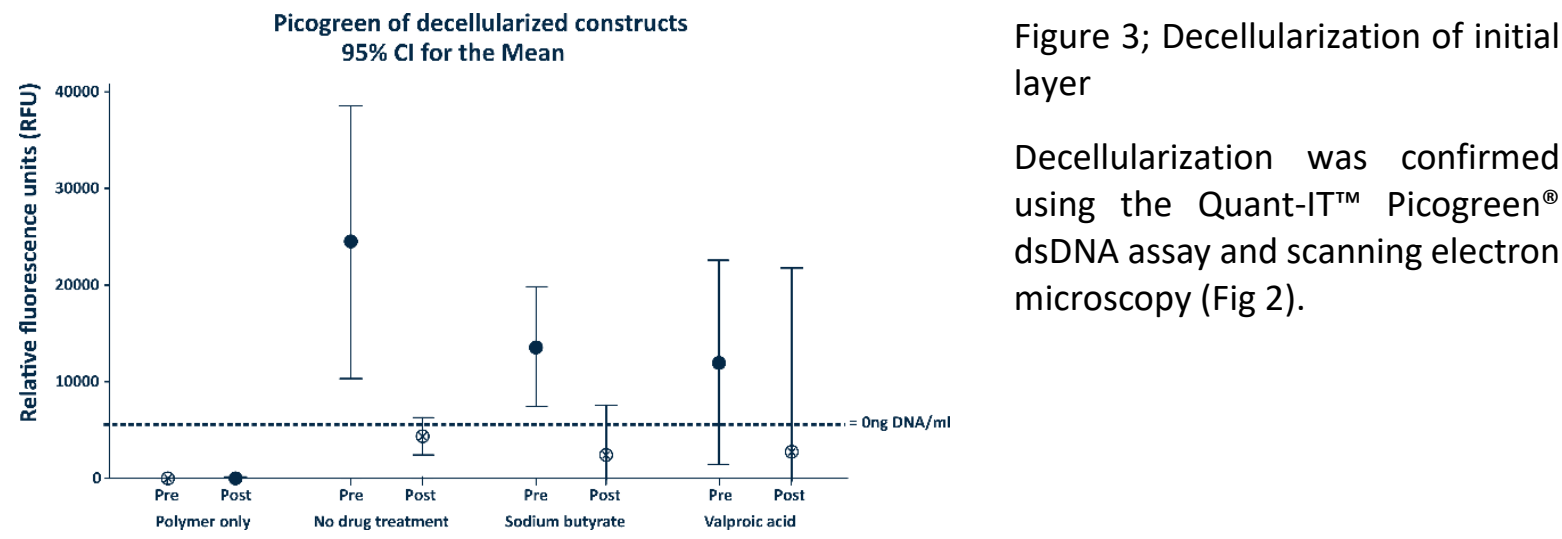

\section{Cell survival and metabolism}

As demonstrated in the SEM imaging (Fig 2) primary human hepatocytes have adhered to the scaffold successfully. This is confirmed by Picogreen DNA and MTT analysis (Fig 4). As expected due to early cell death, DNA levels drop off after 24 hours. They recover slightly, although not significantly, at 120 hours. MTT absorbance results demonstrate that cells are metabolically active at each time point, and that this metabolic activity increases over time.

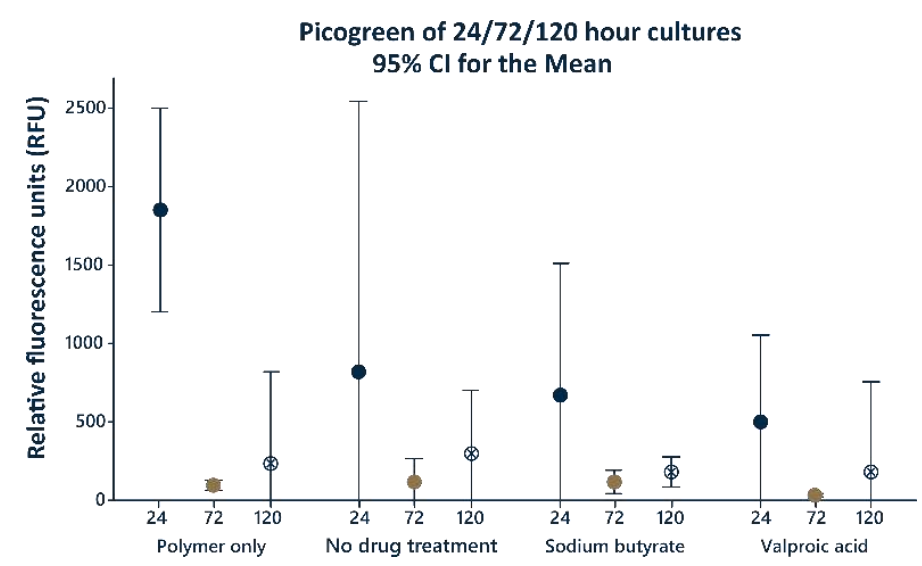

MTT assay

$95 \% \mathrm{Cl}$ for the Mean
Figure $\quad 4 ; \quad$ Seeding

efficiency/viability on scaffolds

Cell adherence was assessed by Quant-IT ${ }^{\mathrm{TM}} \quad$ Picogreen $^{\circledR}$ dsDNA assay and metabolic viability confirmed by MTT absorbance assay One-way ANOVA with Tukey post hoc testing. ${ }^{*}=p<0.05^{* *}=$ $p<0.01$. Error bars represent SD.

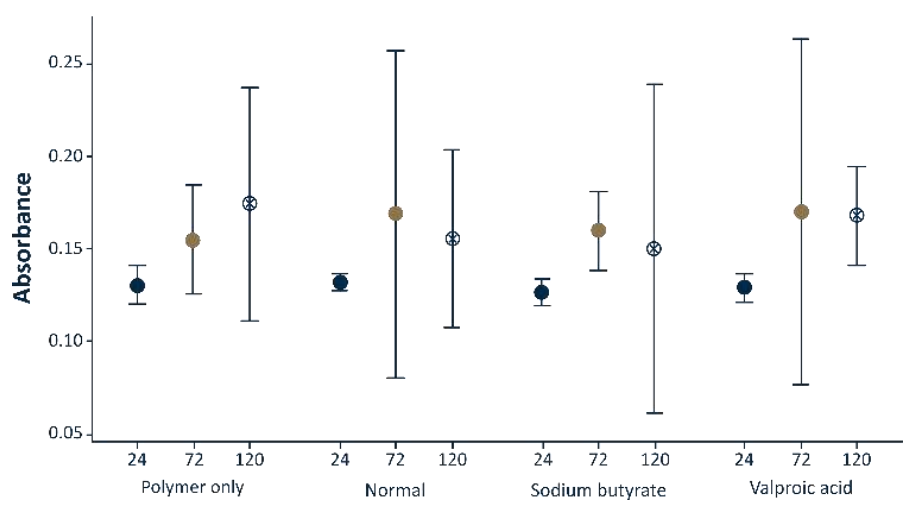




\section{Albumin production}

Figure 5 reveals that albumin is being produced by the primary human hepatocytes in each condition and at each time point. Importantly, albumin levels are significantly higher than those produced on tissue culture plastic at 24 hours on every scaffold. On PO scaffolds, albumin production increases significantly between 72 and 120 hours. Importantly, the pattern of albumin production reassuringly tallies that of the MTT metabolic analyses (Fig 4), indicating an initial metabolic drop off and then recovery over the 120 -hour culture period.

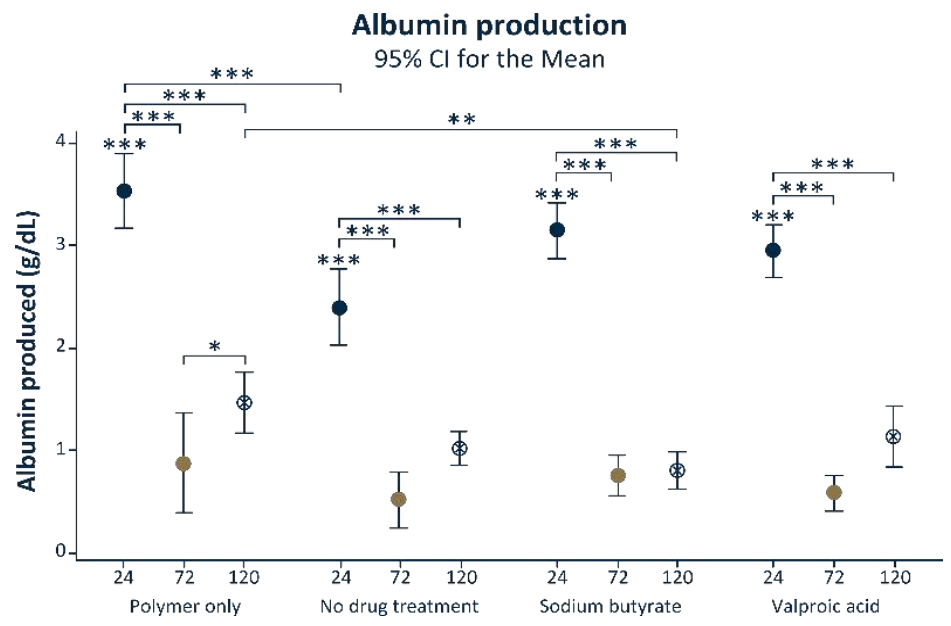

Figure 5; Albumin production on scaffolds

Cell function was assayed by checking for albumin protein production. One-way ANOVA with Tukey post hoc testing. ${ }^{*}=p<0.05$ $* *=p<0.01$. Error bars represent SD.

\section{Immunohistochemistry}

Differences in the biochemical profile of the different ECMs were demonstrated by immunohistochemistry performed on the hybrid scaffold sections (Fig 6). As discussed previously, hepatic phenotype and behaviour has long been known to be influenced by ECM composition; particularly Collagen I, Laminin and Fibronectin ${ }^{24,37,38}$, all of which are present on the scaffolds to varying degrees (stained in red). The PLA fibres are clearly visible in each. Laminin is of particular

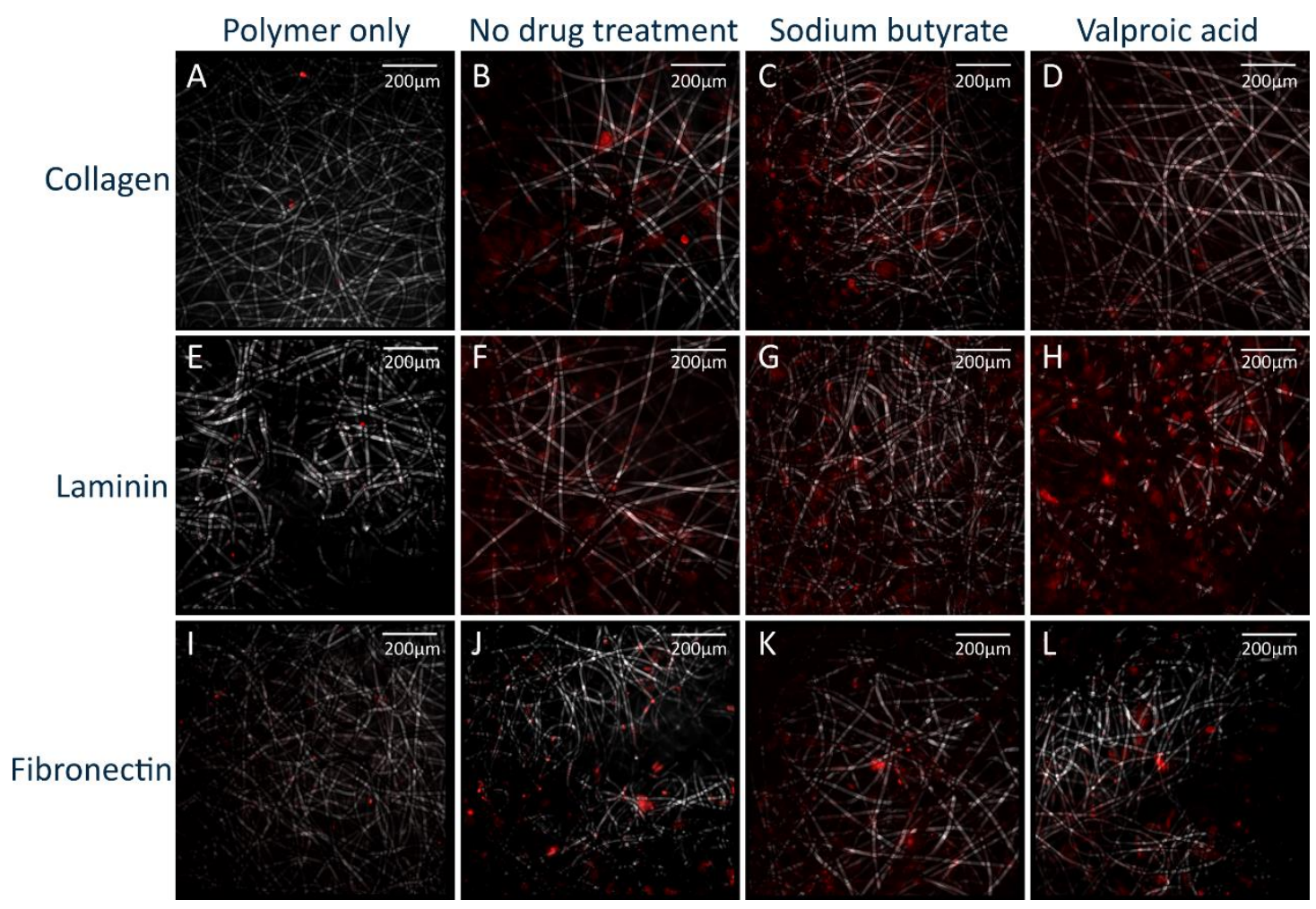


Figure 6; Immunohistochemical investigation

Immunohistochemistry staining of the decellularized ECM/scaffold constructs revealed significant differences in $E C M$ components. Stains were performed for Collagen I $(A, B, C, D)$, Laminin $(E, F, G, H)$ and Fibronectin $(\mathrm{I}, \mathrm{J}, \mathrm{K}, \mathrm{L})$, post processed using ImageJ.

importance in the regenerating liver and for cell adhesion, and is increased in injured or developing states $^{18,39}$. Laminin seem most prevalent on VA-ECM scaffold constructs (Fig $6 \mathrm{H}$ ), followed by NaBECM (Fig 6G) and N-ECM (Fig 6F) scaffold constructs. Collagen I is one of the major components of normal liver $\mathrm{ECM}^{37,38}$. Collagen I appears most prevalent on NaB-ECM scaffold constructs (Fig $6 \mathrm{C}$ ), followed by VA-ECM (Fig 6D) and N-ECM (Fig 6B) scaffold constructs. These results were also seen in the previous iteration of this work ${ }^{23}$. When compared to the N-ECM scaffold constructs, these demonstrate improved albumin production (Fig 5). Fibronectin is also ubiquitous in healthy liver $\mathrm{ECM}^{37,40}$. Fibronectin staining is present in each construct (Fig 6J, 4.6K \& 4.6L).

Staining was also undertaken to visualise the hepatocytes adhered to the scaffolds (Fig 7). Cells are visible in each condition and at each time point, although spread far apart. This reflects the relatively low seeding density of the hepatocytes.

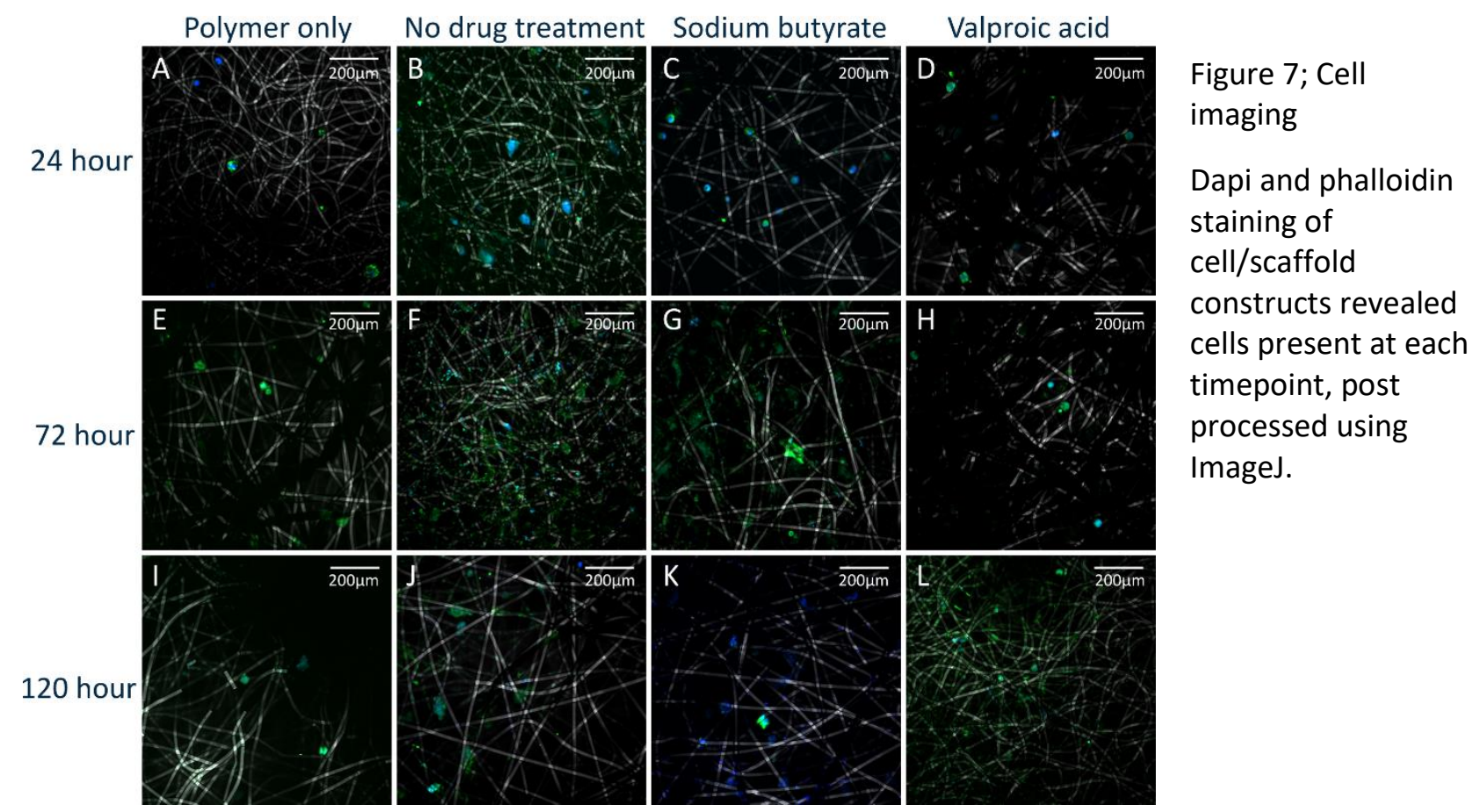

\section{Gene expression}

Gene expression analysis demonstrates significant differences between condition and time points (Fig 8). Albumin gene expression (Fig 8A) is altered between PO at 24 hours on ND-ECM and 72 hours on V-ECM. Differences are also seen at 72 hours between ND-ECM, V-ECM and NaB-ECM as well as between each time point on N-ECM. Of not is that the gene expression follows a similar pattern to that of the albumin production; high at 24 hours then dropping off at 72 hours before recovering at 120 hours in each condition. CYP1A2 expression (Fig 8B) is altered at 24 hours between PO-ECM, N$E C M, V-E C M$ and NaB-ECM with changes also seen between time points on N-ECM. Col4A1 expression (Fig 8F) demonstrated changes between time points in the N-ECM condition, and FN1 (Fig 8G) expression is significantly altered at 24 hours between all conditions, similarly to that of CYP1A2 expression. 

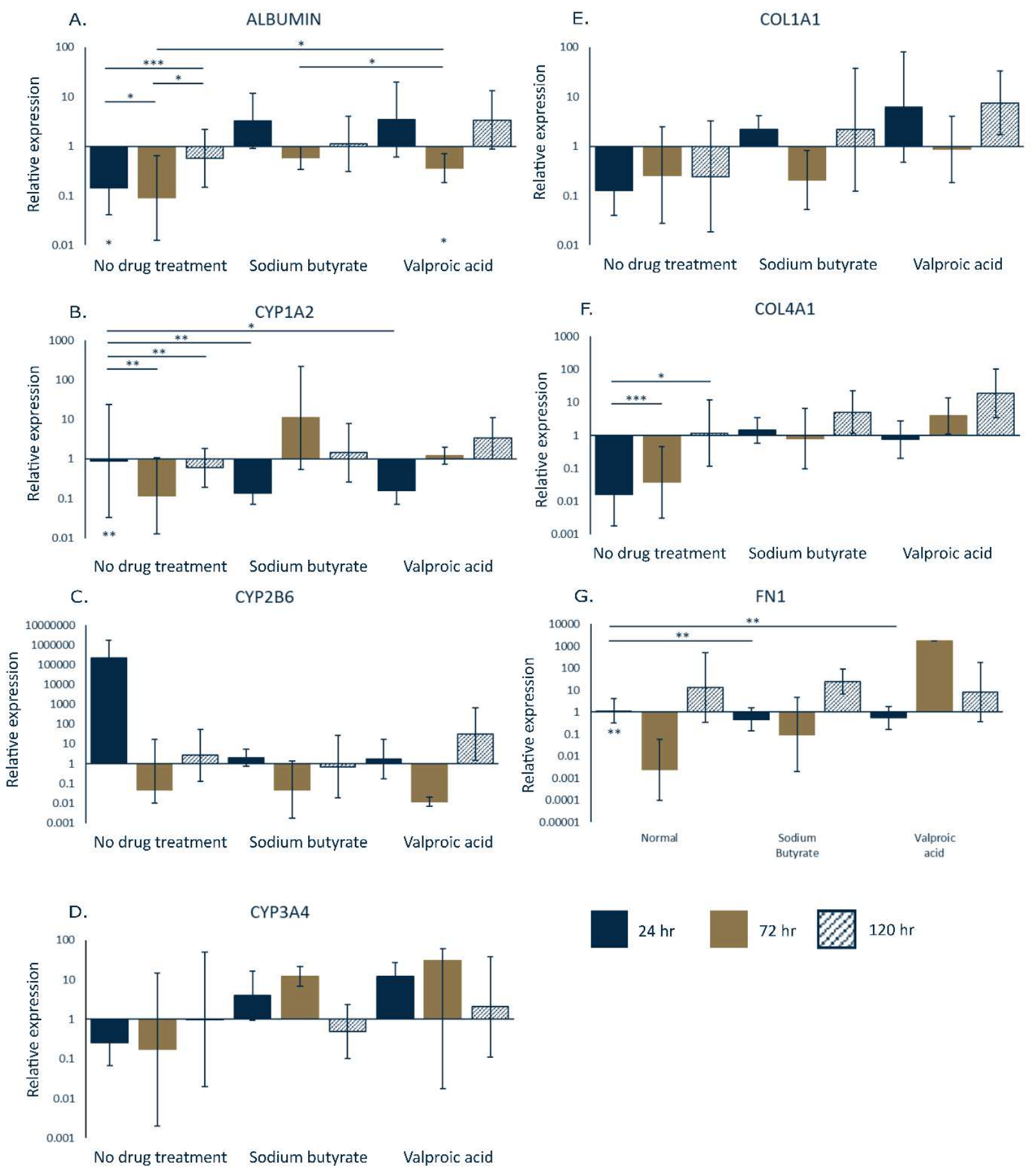

Figure 8; Q-PCR analysis of functional cell layer

Quantitative analysis of gene expression was undertaken on the functional cell layer 24, 72 and 120 hours culture, compared to that of the polymer only condition at each timepoint. mRNA levels of Albumin (A), CYP1A2 (B), CYP2B6 (C), CYP3A4 (D), Collagen I (E) Collagen IV (F), and Fibronectin $(G)$ are represented as fold difference relative to tissue culture plastic controls and relative to the housekeeping gene GAPDH. One-way ANOVA with Games-Howell post hoc testing and minimum $n=4 .{ }^{*}=p<0.05 * *=p<0.01$. Error bars represent SD. 


\section{Discussion}

The production of an alternative to whole organ transplant for treatment of liver disease patients is a vital avenue for research in the face of increasing donor shortages, treatment costs and disease burden on national healthcare systems. Equally, the analysis of primary hepatocyte behaviour on manufactured culture environments is vital to the field of liver biology. A platform which can produce consistent, clinically translatable scaffolds for liver cell survival and function would go some way to furthering our knowledge of hepatocyte biology, liver disease and provide a potential treatment and drug testing bed without involving the use of animals and animal tissues.

An electrospun fibre approach was taken in the study to mimic the morphology of healthy fibrillary collagen ${ }^{41,42}$, a major constituent of the human liver extracellular matrix in vivo. We selected PLA for the fabrication of electrospun scaffolds due to its biodegradable nature and elasticity ${ }^{28}$, and it's previous use in liver scaffolding studies ${ }^{20,43}$.

The hepatic ECM is a highly plastic biomaterial, subject to constant modification and varies massively between tissues ${ }^{44}$, and between healthy and diseased livers ${ }^{45,46}$. As the ECM is such a dynamic structure, it stands to reason that its production and maintenance will be influenced by its surrounding environment in 3D culture ${ }^{30}$. Previous work revealed that histone deacetylase inhibitors (iHDACs) do indeed alter ECM production in culture, thus we used these iHDACs to manipulate the cellular environment and alter the ECM production. Sodium butyrate $(\mathrm{NaB})$ is widely used in industry to increase yield recombinant protein yields in mammalian cells. Valproic acid (ValA) is an FDA approved anti-convulsant which also functions as an iHDAC to increase recombinant protein yields ${ }^{47}$. Histone deacetylase inhibitors influence gene expression via their role in deacetylation; the process by which DNA renders itself less transcriptionally active. Inhibiting this process in cells results in hyperacetylation of histones and subsequently increases transcriptional activity ${ }^{33}$. Once again, results indicate not only that the iHDACs significantly alter the production and consistency of the ECM, but that this technique is robust and reproducible and the ECM it produces, when harnessed in combination with 3D scaffolding technologies, creates a biofuctionalized scaffold which significantly alters the behaviour of liver cells. Equally, these scaffolds can be simply stored by freezing and remain biologically active for subsequent seeding of primary human hepatocytes.

Previous work took advantage of a bladder epithelial cell line for the initial ECM producing cell layer, however in this instance we progressed to using THLE-3 liver cells; a cell line derived from normal primary liver cells derived from the left lobe of a human liver. The cell line was immortalized via infection with SV4O large T antigen and expresses the phenotypic characteristics of normal adult liver epithelial cells. They are non-tumorigenic when injected into athymic nude mice, have near-diploid karyotypes, and do not express alpha-fetoprotein. THLE-3 cells metabolize benzo(a)pyrene, Nnitrosodimethylamine, and aflatoxin B1 to their ultimate carcinogenic metabolites that adduct DNA, which indicates that they possess functional cytochrome P450 pathways ${ }^{48,49}$. By using THLE-3s, we address minor concerns that the ECM produced by the initial cell layer is not a 'liver ECM' and that this may have an influence on the functional cell layer. However, multiple studies and product continue to use inter-organ and even multi-animal sources of ECM. Several decellularized ECM products on the market are in clinical use to regenerate tissues from which they are not derived, including ALLOPATCH HD' ${ }^{\mathrm{TM}}$, MatriStem ${ }^{\circledR}$ and Tutoplast ${ }^{\circledast}$ Pericardium $^{50}$. Indeed, hepatocytes are often cultured on ' $E C M$ ' surfaces which are not derived from liver, commonly using Matrigel $^{\circ}$, a product derived from murine sarcoma which is as yet undefined and experiences batch to batch variability 24,51-54. The promising field of whole organ decellularization is hampered by the availability of human livers, and researchers are subsequently investigating alternative organ and cells sources, such as spleen, bone marrow mesenchymal stem cells ${ }^{55,56}$ and various animal sources of livers ${ }^{57}$. With this body of knowledge in mind, we maintain that hepatocytes may respond equally favourably to non-liver ECM and remain open to other sources of ECM for hybrid scaffold manufacture as a result.

The use of primary human hepatocytes was undertaken to address concerns regarding the more commonly used cell lines. Previous work to assess the performance of the hybrid scaffolds, was 
undertaken using the HepG2 cell line; derived from the hepatocarcinoma of a 15-year-old Caucasian male. While results obtained from HepG2s are valuable they are limited in their translatability because they are derived from a carcinoma and are tumourigenic. By taking advantage of the rare resource we have in our donor human livers, we increase the clinical translatability of this hybrid scaffold platform and elucidate further knowledge of the behaviour of primary human hepatocytes in an engineered culture environment. We analysed cell attachment and metabolic viability, and gene expression of both liver function genes and ECM genes at both 24, 72 and 120-hour time points. Additionally, we validated the decellularization of the ECM producing cell layer and performed immunohistochemical analyses of the hybrid scaffold-ECM constructs upon which the HepG2s were seeded.

This work is a robust body of 'next stage' research regarding manipulation of ECM production, and has produced a repeatable method of hybrid polymer-ECM scaffolds with great potential for liver tissue engineering and shown that these scaffolds can be stored for future use and maintain bioactivity and sterility. Further work is required to analyse results and increase translatability. Our primary human hepatocytes are a highly valuable research resource; however, our donors are derived from a pool of individuals whose organs are rejected for whole organ transplant into living recipients. This indicates that their livers, and therefore their hepatocytes are not in the utmost of health. Further work should ideally be undertaken using healthy human donor hepatocytes. Furthermore, while hepatocytes are the major parenchymal cell of the liver (making up more than $70 \%$ of the cellular mass), they do not exist in isolation and the non-parenchymal cells play an essential role in the in vivo liver ${ }^{58,59}$; future studies should look to include a co-culture element. In addition, recognising the value of proteomic and functional assays (such as ELISAs) in analysing the function of the primary/stem cell derived hepatocytes will be important for future validation of the scaffolds, however at this time these were deemed unnecessary considering the health of the donor hepatocytes Researchers harnessing this method should take care to ensure decellularization agents are completely removed from the scaffolds, due to their deleterious effect on both cells and $\mathrm{ECM}^{60}$. While such considerations are of importance, this study clearly demonstrates the potential of these hybrid polymer-ECM scaffolds for tissue engineering and provides a robust initial platform for further research.

\section{Conclusion}

This study developed a new method of creating hybrid polymer-ECM scaffolds by manipulating cells using electrospun scaffold technologies, clinically relevant iHDACs and methods easily modified to fulfil good manufacturing practice (GMP) regulation. To do so, a sacrificial, ECM-producing cell layer was seeded onto a novel electrospun scaffold and then treated with valproic acid or sodium butyrate to biofuctionalize the scaffold with ECM components. Scaffolds with untreated cells and no initial cell layer at all were used as controls. The initial cell layer was removed with a detergent based decellularization method, and the resulting hybrid polymer-ECM scaffolds were stored at $-80^{\circ} \mathrm{C}$ until a source of donor primary human hepatocytes was available for use as a functional cell layer. The work was validated using robust methods such as Q-PCR, mechanical quantification and scanning electron microscopy. Drug induced hybrid polymer-ECM scaffolds had a significant positive influence on the gene expression profile and albumin production of primary human hepatocytes. Our data demonstrates promise as a unique method of inducing and altering the production of ECM and that the hybrid scaffolds exert influence upon cells in vitro, as well as future potential as an implantable treatment platform for liver disease patients and testing bed for development of novel pharmaceuticals and treatments for liver disease, as well as the study of primary hepatocyte biology and behaviour. 


\section{Materials and Methods}

Methods were performed in accordance to previously published methods ${ }^{23}$, summarized here.

\section{Ethics and Governance}

All human donor tissue used in this study was provided by NHS Organ Donation and Transplant and NHS Blood and Transplant. No organs or tissues were procured from prisoners. Ethical approval was granted for the project from the North of Scotland Research Ethics Committee, ref 16/NS/0083. Informed consent for organ donation for research purposes was obtained in accordance with the Helsinki Declaration.

\section{Electrospinning}

A 22\% wt/vol solution of hexafluoroisopropanol (Manchester Organics) and poly-L-lactic acid (Goodman) was dissolved overnight at room temperature with agitation.

Solutions were placed into a $10 \mathrm{ml}$ syringe and pumped using syringe pump EP-H11 (Harvard Apparatus) into an EC-DIG electrospinning system (IME technologies) via a 27G bore needle under the following parameters (Table 2);

Table 2; Electrospinning parameters

\begin{tabular}{ccccccc}
\hline $\begin{array}{c}\text { Volume } \\
\text { per hour }\end{array}$ & Total volume & $\begin{array}{c}\text { Mandrel:needle } \\
\text { distance }\end{array}$ & $\begin{array}{c}\text { Positive } \\
\text { charge }\end{array}$ & $\begin{array}{c}\text { Negative } \\
\text { charge }\end{array}$ & $\begin{array}{c}\text { Mandrel } \\
\text { rotation }\end{array}$ & $\begin{array}{c}\text { Needle } \\
\text { movement }\end{array}$ \\
\hline $2.5 \mathrm{ml}$ & $7.5 \mathrm{ml}$ & $23 \mathrm{~cm}$ & $16 \mathrm{kV}$ & $-3 \mathrm{kV}$ & $300 \mathrm{rpm}$ & $100 \mathrm{~mm} / \mathrm{s}$ \\
\hline
\end{tabular}

The rotating mandrel was wrapped in non-stick aluminium foil to collect the sheet of electrospun fibres. The sheets of electrospun fibres were allowed to dry overnight in a fume hood when the electrospinning session was completed and used immediately. An average fibre diameter of $1.82 \mu \mathrm{m}$ was calculated by ImageJ plugin 'DiameterJ' 61 .

\section{Scaffold Preparation}

$10 \mathrm{~mm}$ discs of scaffold were cut out using a biopsy punch from the dry electrospun fibre sheet. The scaffolds were sterilised using the following procedure; soaked in 30\% isopropyl alcohol for 10 minutes, then rinsed three times in phosphate buffered saline (PBS) for 15 minutes each. Then transferred to sterilisation media and incubated for 1 hour at $37^{\circ} \mathrm{C}$ (Table 3 ).

\section{Initial Layer Cell Seeding and Culture}

Post-sterilisation, scaffolds were rinsed three times for 15 minutes each in complete media (Table 3 ). They were then placed into a fresh 48 well tissue culture plate.

THLE-3 immortalized normal human liver epithelials (ATCC) were trypsinized using standard methods from tissue culture flasks and counted using the trypan blue exclusion method. $3.5 \times 10^{4}$ cells at passage 4 were suspended in $100 \mu \mathrm{l}$ of complete media and seeded directly on to the scaffolds. The cells were allowed to incubate in this small volume on the scaffolds for 3 hours to allow attachment, before an additional $400 \mu \mathrm{l}$ of complete media was added.

Media was changed after 24 hours to either $750 \mu \mathrm{M}$ Valproic Acid (VA-ECM) or $750 \mu \mathrm{M}$ Sodium Butyrate (NaB-ECM) (Sigma-Aldrich) in complete media and changed every 48 hours. Controls were polymer only (PO), i.e. not seeded with an initial cell layer at all and no drug treatment (N-ECM) i.e. the initial layer was cultured in drug free complete media only and never exposed to either iHDAC. Drug concentrations and initial layer cells were chosen following results of a drug response curve for each iHDAC (data not shown). Valproic acid and sodium butyrate are used as epigenetic control mechanisms of gene transcription. This initial layer of cells was cultured for 7 days at $37 \stackrel{\circ}{ } \mathrm{C}$ and $5 \% \mathrm{CO}_{2}$ in a humidified incubator. 


\section{Decellularization}

Decellularization was performed using methods adjusted from Lu et al. $(2012)^{62}$, under sterile conditions at room temperature $(19-22 \circ \mathrm{C})$ and with agitation. Scaffolds were washed in PBS for 15 minutes and then rinsed in $10 \mathrm{mM}$ tris buffered saline (TBS) for 15 minutes.

The scaffolds were submerged in decellularization media (Table 3 ) for 4 hours. They were rinsed for 15 minutes in $10 \mathrm{mM}$ TBS before being submerged in fresh $10 \mathrm{mM}$ TBS overnight.

Scaffolds were given a final rinse in $10 \mathrm{mM}$ TBS for 15 minutes before being transferred to $500 \mu \mathrm{l}$ fresh PBS in new 48 well culture plates. Plates were sealed with parafilm and flash-frozen in a dry ice:ethanol bath. Samples were stored at $-80 \circ \mathrm{C}$ until use.

\section{Percoll primary hepatocyte extraction}

The donor liver had been subject to ex situ normothermic perfusion as part of another groups ongoing research ${ }^{63}$ prior to collection. Upon receipt of the donated liver 10 small $\left(2 \mathrm{~cm}^{2}\right)$ chunks of liver tissue were incubated in a $10 \mathrm{~cm} 2$ petri dish with digest media (Table 3 ) and minced finely with scalpels. The digest:tissue mixture was incubated at $37^{\circ} \mathrm{C}$ for 30 minutes and filtered through a $70 \mu \mathrm{m}$ cell strainer (Corning).

The resulting filtrate was centrifuged at $135 \mathrm{~g}$ for 1 minute at room temperature, and the supernatant then layered onto a gradient of $5 \mathrm{ml} 1.06 \mathrm{~g} / \mathrm{ml}, 5 \mathrm{ml} 1.08 \mathrm{~g} / \mathrm{ml}$ and $3 \mathrm{ml} 1.12 \mathrm{~g} / \mathrm{ml}$ Percoll ${ }^{\circ}$. The sample was then centrifuged at $750 \mathrm{~g}$ for 20 minutes at room temperature, and the phase between $1.06 \mathrm{~g} / \mathrm{ml}$ and $1.08 \mathrm{~g} / \mathrm{ml}$ collected. The hepatocytes were cleaned with $50 \mathrm{ml}$ blank Williams E media at $135 \mathrm{~g}$ for 1 minute at room temperature and plated onto tissue culture plastic or scaffolds as needed.

\section{Functional layer Cell Seeding and Culture}

The primary hepatocytes were seeded at $3 \times 10^{5}$ cells, suspended in $100 \mu$ l of PHH media (Table 3 ) and placed directly on to the scaffolds. The cells were allowed to incubate in this small volume on the scaffolds for 2 hours, before an additional $400 \mu l$ of complete media was added.

The primary hepatocytes do not expand, and media was changed every 24 hours. This functional layer $(\mathrm{FL})$ of cells was cultured using standard methods for either 24,72 or 120 hours at $37{ }^{\circ} \mathrm{C}$ and $5 \% \mathrm{CO}_{2}$ in a humidified incubator.

Table 3; Media types

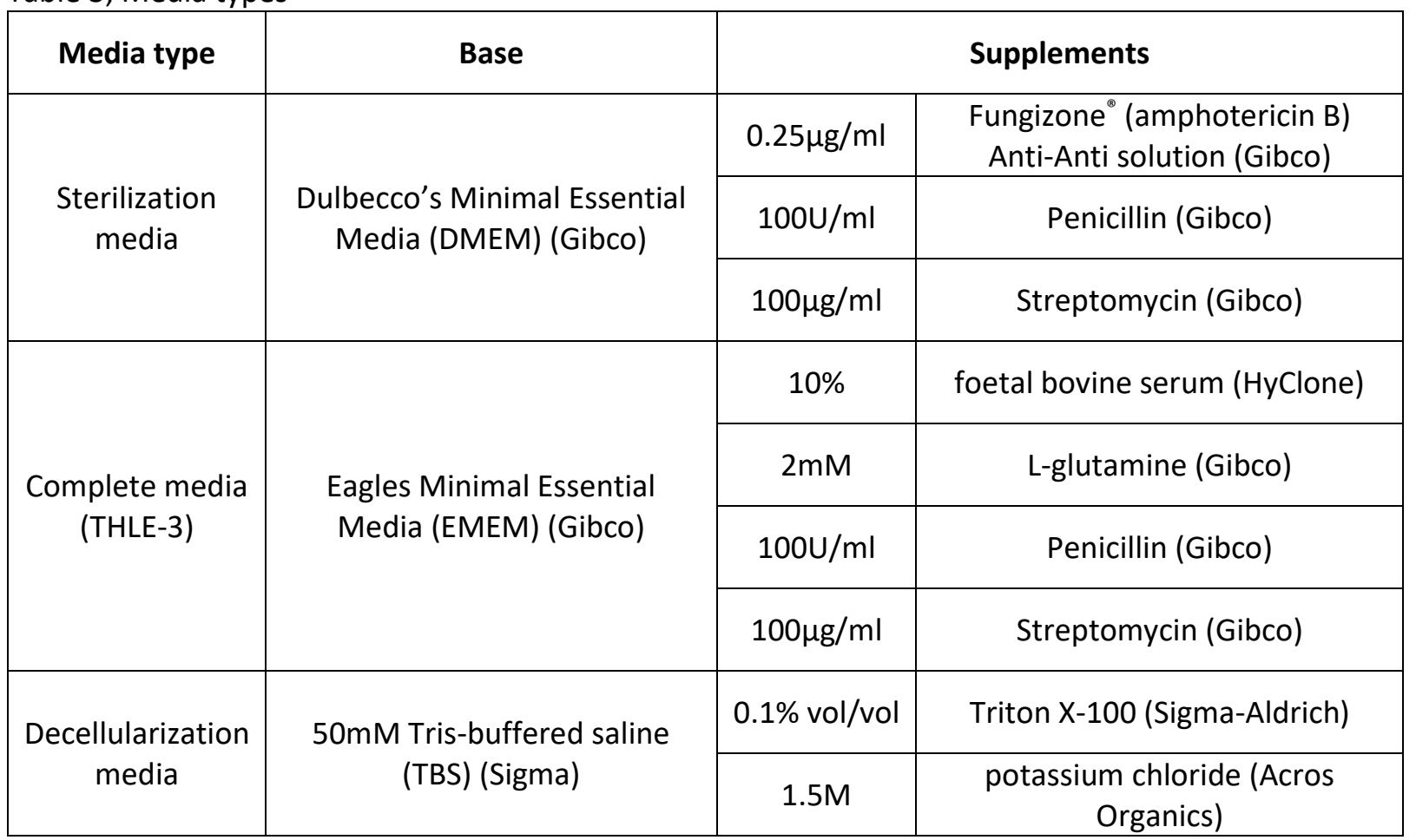




\begin{tabular}{|c|c|c|c|}
\hline \multirow{2}{*}{ Digest media } & \multirow{2}{*}{$\begin{array}{l}\text { Dulbecco's Minimal Essential } \\
\text { Media (DMEM) (Gibco), }\end{array}$} & $0.05 \%$ & Trypsin-EDTA (Gibco), \\
\hline & & $0.625 \mathrm{mg} / \mathrm{ml}$ & Collagenase I (Sigma) \\
\hline \multirow{9}{*}{ PHH media } & \multirow{9}{*}{$\begin{array}{l}\text { Williams E media with no } \\
\text { phenol red (Gibco) }\end{array}$} & $10 \%$ & foetal bovine serum (HyClone) \\
\hline & & $2 \mathrm{mM}$ & L-glutamine (Gibco) \\
\hline & & $100 \mathrm{U} / \mathrm{ml}$ & Penicillin (Gibco) \\
\hline & & $100 \mu \mathrm{g} / \mathrm{ml}$ & Streptomycin (Gibco) \\
\hline & & $1 \%$ & $\begin{array}{c}\text { Non-essential amino acids } \\
\text { (Gibco) }\end{array}$ \\
\hline & & $1 \%$ & Sodium pyruvate (Gibco) \\
\hline & & $2 \mu \mathrm{g} / \mathrm{ml}$ & Hydrocortisone (Sigma) \\
\hline & & $0.124 \mathrm{IU} / \mathrm{ml}$ & Human insulin (Sigma) \\
\hline & & $1 \mu \mathrm{g} / \mathrm{ml}$ & $\begin{array}{l}\text { Human epidermal growth factor } \\
\text { (Corning) }\end{array}$ \\
\hline
\end{tabular}

\section{Live/Dead ${ }^{\circledR}$ Viability/Cytotoxicity assay}

Live/dead assessment was performed in accordance to standard methods ${ }^{64}$. Briefly, cell/scaffold constructs were incubated with $10 \mu \mathrm{m}$ calcein and $2 \mu \mathrm{m}$ ethidium homodimer-1 (Ethd-1) for 30 minutes as part of the two colour live/dead assay (Molecular Probes). The scaffolds were rinsed three times in $\mathrm{CaCl}_{2} / \mathrm{MgCl}_{2}$ free PBS to remove excess dye and placed onto a standard microscope slide with a $25 \mathrm{~mm}$ glass coverslip (VWR). All images were captured using a Zeiss Axio Imager fluorescent microscope (COIL, University of Edinburgh) at 40x magnification and post processed using ImageJ.

\section{$\mathrm{MTT}^{\circ}$ Cell viability assay}

The MTT (3-(4,5-dimethylthiazol-2-yl)-2,5-diphenyltetrazolium bromide) assay was performed in accordance to standard methods ${ }^{65}$. Briefly, the primary hepatocyte functional cell layer was incubated with MTT for 2 hours at the 24, 72 and 120-hour time points. Cells were solubilized prior to recording absorbance readings using acidic isopropanol (Sigma) and measurements were read in a Modulus ${ }^{\mathrm{TM}}$ II microplate reader at a wavelength of $570 \mathrm{~nm}$ and reported as absorbance.

\section{Albumin quantification}

A bromocresol green (BCG) albumin assay (Sigma) was used to quantify serum albumin produced by the primary hepatocyte functional cell layer over 24 hours at 24,72 and 120 hours. The assay was performed according to manufacturer's instructions ${ }^{66}$ and results read at an absorbance of $620 \mathrm{~nm}$ in a Modulus ${ }^{\mathrm{TM}}$ II microplate reader. For each condition group, minimum $\mathrm{n}=5$.

\section{Picogreen ${ }^{\circ}$ DNA quantification}

The Quant-IT $T^{\mathrm{TM}}$ Picogreen ${ }^{\circ}$ dsDNA assay kit (Life Technologies ${ }^{\mathrm{TM}}$ ) was used to establish the efficiency of the decellularization and assess cell number on the cell/scaffold constructs. The assay was performed according to manufacturer instructions ${ }^{67}$. In brief, constructs (minimum $n=5$ ) were digested in a solution of $\mathrm{CaCl}_{2}$ and $\mathrm{MgCl}_{2}$ free PBS (Sigma) containing $2.5 \mathrm{U} / \mathrm{ml}$ papain extract (Sigma) $5 \mathrm{mM}$ cysteine- $\mathrm{HCl}$ (Sigma) and $5 \mathrm{mM}$ EDTA (Sigma) and incubated for 48 hours at $60^{\circ} \mathrm{C}$. Picogreen solution was added to the digests and fluorescent intensity measurements read in a Modulus ${ }^{\mathrm{TM}}$ II 
microplate reader at an excitation wavelength of $480 \mathrm{~nm}$ and emission wavelength of $510-570 \mathrm{~nm}$. A standard $\lambda$ dsDNA curve of graded known concentrations was used to calibrate fluorescence intensity vs dsDNA concentration.

\section{Immunohistochemistry}

Immunohistochemistry was performed to assess protein composition and cell adherence on the scaffolds. Briefly, samples were rinsed three times in PBS (Gibco) for 15 minutes each, then fixed in $4 \% \mathrm{v} / \mathrm{v}$ formalin buffered in saline for 1 hour at room temperature. After rinsing with fresh PBS, constructs were stained overnight using antibodies for Collagen I (Stratech), Laminin (Stratech) and Fibronectin (Sigma). Top down images of cells on the scaffolds were obtained by staining with DAPI (Sigma) and Phalloidin (Sigma). All images were captured using a custom multi-photon microscope at the Institute for Bioengineering Bioimaging Facility, University of Edinburgh. A mode-locked ND:YVO4 laser source (PicoTrain, Spectra Physics) was used to generate both a Stokes pulse (6 ps, $1064 \mathrm{~nm}$ ) and drive an optical parametric oscillator (OPO) (Levante Emerald, APE). The OPO provides a tuneable excitation pulse across 700-1000 nm allowing coherent anti- Stokes Raman scattering (CARS), second harmonic generation (SHG) and two-photon excitation fluorescence (TPEF) microscopy.

\section{Scanning Electron Microscopy}

SEM was used to characterise scaffold architecture using previously published methods ${ }^{65}$. Samples were rinsed three times in PBS for 15 minutes each, and fixed in $2.5 \% \mathrm{v} / \mathrm{v}$ glutaraldehyde (Fisher Scientific) in $0.1 \mathrm{M}$ phosphate buffer (PB) $(\mathrm{pH} 7.4)$ at $4^{\circ} \mathrm{C}$ overnight. They were then rinsed three times in $0.1 \mathrm{M}$ PB before being post-fixed in $1 \% \mathrm{v} / \mathrm{v}$ osmium tetroxide (Electron Microscopy Supplies) buffered with 0.1M PB. Samples were again rinsed three times in 0.1M PB and dehydrated through an ethanol gradient (30-100\%). They were dried by placing them in hexamethyldisilane (HDMS, Sigma) which was allowed to evaporate off at room temperature overnight. Samples were mounted onto SEM chucks using double sided carbon tape and coated with a thin layer of gold and palladium alloy (Polaron Sputter coater).

All images were captured at $5 \mathrm{kV}$ using a Hitachi S-4700 SEM (BiOSEM, University of Edinburgh).

\section{Mechanical Testing}

Compression testing was undertaken to establish the dynamic properties of the hybrid polymer:ECM scaffolds using the Instron 3367 dual column universal testing system with Bluehill 3 software. Each sample was compressed to $10 \%$ strain at a crosshead speed of $0.5 \%$ strain min- 1 . Incremental compressive moduli were calculated from $0 \%-2.5 \%, 2.5 \%-5 \%, 5 \%-7.5 \%$ and $7.5 \%-10 \%$, adapted from previous methodology ${ }^{28,41}$.

\section{Gene Expression analysis}

RNA was extracted from constructs using standard Trizol (Fisher Scientific) methods and purified using Qiagen's RNeasy spin column system. cDNA was synthesised using the Promega's ImProm-II ${ }^{\mathrm{TM}}$ Reverse Transcription System.

Quantitative real-time polymerase chain reaction (qRT-PCR) was performed using the LightCycler ${ }^{\circ} 480$ Instrument II (Roche Life Science) and Sensifast ${ }^{\mathrm{TM}}$ SYBR $^{\circ}$ High-ROX (Bioline) system. Results were normalized to primary hepatocytes of the same extraction grown on polymer only scaffolds and compared to the housekeeping gene Glyceraldehyde-3-Phosphate Dehydrogenase (GAPDH). Analysis was performed using the 2-[delta][delta] Ct method ${ }^{68,69}, \mathrm{n}=5$. Albumin (Alb), Cytochrome P450 Family 1 Subfamily A Polypeptide 2 (Cyp1A2), Cytochrome P450 Family 2 Subfamily B Polypeptide 6 (Cyp2B6), Cytochrome P450 Family 3 Subfamily A Polypeptide 4 (Cyp3A4), Collagen Type I alpha 1 (Col1A1), Collagen Type 4 alpha 1 (Col4A1) and Fibronectin Type 1 (FN1) were investigated, forward and reverse primers (Sigma) are detailed in Table 4. 
Table 4; qRT-PCR primers used

\begin{tabular}{|c|c|}
\hline Albumin (Alb) & $\begin{array}{l}\text { For - CCTGTTGCCAAAGCTCGATG } \\
\text { Rev - GAAATCTCTGGCTCAGGCGA }\end{array}$ \\
\hline Cytochrome P450 Family 1 Subfamily A & For - CTTCGCTACCTGCCTAACCC \\
\hline Polypeptide 2 (Сyp1A2) & Rev - GTCCCGGACACTGTTCTTGT \\
\hline Cytochrome P450 Family 2 Subfamily B & For - TGCCCCTTTTGGGAAACCTT \\
\hline Polypeptide 6 (Cyp2B6) & Rev - ATGAGGGCCCCCTTGGATTT \\
\hline \multirow{2}{*}{$\begin{array}{c}\text { Cytochrome P450 Family } 3 \text { Subfamily A } \\
\text { Polypeptide } 4 \text { (Cyp3A4) }\end{array}$} & For- TTTTTTGGATCCATTCTTTCTCTCAA \\
\hline & Rev- TCCACTCGGTGCTTTTGTGT \\
\hline \multirow{2}{*}{ Collagen Type I alpha 1 (Col1A1) } & For - GGACACAGAGGTTTCAGTGGT \\
\hline & Rev - GCACCATCATTTCCACGAGC \\
\hline \multirow{2}{*}{ Collagen Type 4 alpha 1 (Col4A1) } & For - GACCCCCGGGAGAAATAGGT \\
\hline & Rev - TTTGAAAAAGCAATGGCACTCC \\
\hline \multirow{2}{*}{ Fibronectin Type 1 (FN1) } & For - GAACAAACACTAATGTTAATTGCCC \\
\hline & Rev - TCTTGGCAGAGAGACATGCTT \\
\hline Glyceraldehyde-3-Phosphate Dehydrogenase & For - GTCTCCTCTGACTTCAACAG \\
\hline (GAPDH) & Rev - GTTGTCATACCAGGAAATGAG \\
\hline
\end{tabular}

\section{Statistical Analysis}

One-way ANOVAs with Games-Howell and Tukey post-hoc testing was performed using Minitab 18 Statistical Software. Multiple comparisons tests were used following the Ryan Joiner test for normality and Bartlett's test for the homogeneity of variances. The Tukey post hoc test was used where Bartlett's test result is not significantly different i.e. the null hypothesis of population variances being equal is not rejected. The Games-Howell test does not assume equal variances and sample sizes and was performed on the ranked variables similar to other nonparametric tests. The Games-Howell post hoc test is used where Bartlett's test result is significantly different i.e. the null hypothesis of population variances being equal is rejected. Error bars indicate standard deviation. A minimum of $\mathrm{n}=3$ and $\max$ of $\mathrm{n}=6$ was used for all analysis. ${ }^{*}=\mathrm{p}$ value $<0.05,{ }^{* *}=\mathrm{p}$ value $<0.01,{ }^{* * *}=\mathrm{p}$ value $<0.001$.

Methods are as previously described in published papers ${ }^{128,129}$.

\section{References}

1. Williams, R. et al. The Lancet Commissions Addressing liver disease in the UK : a blueprint for attaining excellence in health care and reducing premature mortality from lifestyle issues of excess consumption of alcohol, obesity, and viral hepatitis. Lancet 384, 1953-1997 (2014).

2. Williams, R. et al. Implementation of the Lancet Standing Commission on Liver Disease in the UK. Lancet 386, 2098-2111 (2015).

3. NHS Blood and Transplant. Organ Donation and Transplantation Activity Report 2018/19. (2020).

4. NHS Blood and Transplant. Organ donation and transplantation Activity Report 2014-2015. (2016).

5. British Association for the Study of the Liver \& British Society of Gastroenterology. A Time to Act: Improving Liver Health and Outcomes in Liver Disease. The National Plan for Liver Services UK (2009).

6. Muriel, P. \& Rivera-Espinoza, Y. Beneficial drugs for liver diseases. J. Appl. Toxicol. 28, 93-103 (2008). 
7. Takebe, T. et al. Vascularized and complex organ buds from diverse tissues via mesenchymal cell-driven condensation. Cell Stem Cell 16, 556-565 (2015).

8. Takebe, T. et al. Vascularized and functional human liver from an iPSC-derived organ bud transplant. Nature 499, 481-4 (2013).

9. Rashidi, H., Alhaque, S., Szkolnicka, D., Flint, O. \& Hay, D. C. Fluid shear stress modulation of hepatocyte-like cell function. Arch. Toxicol. 90, 1757-1761 (2016).

10. Schütte, J. et al. "Artificial micro organs" - a microfluidic device for dielectrophoretic assembly of liver sinusoids. Biomed. Microdevices 13, 493-501 (2011).

11. Zhang, H. et al. Functional liver tissue engineering by an adult mouse liver-derived neuro-glia antigen 2-expressing stem/progenitor population. J. Tissue Eng. Regen. Med. 12, 190-202 (2018).

12. Bale, S. S. et al. Long-Term Coculture Strategies for Primary Hepatocytes and Liver Sinusoidal Endothelial Cells. Tissue Eng. Part C Methods 21, (2015).

13. Cho, C. S. et al. Galactose-carrying polymers as extracellular matrices for liver tissue engineering. Biomaterials 27, 576-85 (2006).

14. Zavan, B. et al. Extracellular matrix-enriched polymeric scaffolds as a substrate for hepatocyte cultures: in vitro and in vivo studies. Biomaterials 26, 7038-45 (2005).

15. Miyauchi, Y. et al. A novel three-dimensional culture system maintaining the physiological extracellular matrix of fibrotic model livers accelerates progression of hepatocellular carcinoma cells. Sci. Rep. 7, (2017).

16. Kang, Y. B., Rawat, S., Cirillo, J., Bouchard, M. \& Noh, H. Layered long-term co-culture of hepatocytes and endothelial cells on a transwell membrane: Toward engineering the liver sinusoid. Biofabrication 5, 1-24 (2013).

17. Binner, M. et al. Cell-instructive starPEG-heparin-collagen composite matrices. Acta Biomater. 53, 70-80 (2017).

18. Martinez-Hernandez, A. \& Amenta, P. S. The extracellular matrix in hepatic regeneration. Faseb J. 9, 1401-1410 (1995).

19. Mazza, G. et al. Rapid production of human liver scaffolds for functional tissue engineering by high shear stress oscillation-decellularization. Sci. Rep. 7, (2017).

20. Grant, R., Hay, D. \& Callanan, A. From scaffold to structure: The synthetic production of cell derived extracellular matrix for liver tissue engineering. Biomed. Phys. Eng. Express 4, (2018).

21. Baiocchini, A. et al. Extracellular matrix molecular remodeling in human liver fibrosis evolution. PLoS One 11, 1-14 (2016).

22. Altrock, E. et al. Inhibition of fibronectin deposition improves experimental liver fibrosis. $J$. Hepatol. 62, 625-633 (2015).

23. Grant, R., Hay, D. \& Callanan, A. A Drug-Induced Hybrid Electrospun Poly-Capro-Lactone: Cell- 
Derived Extracellular Matrix Scaffold for Liver Tissue Engineering. Tissue Eng. Part A 23, 650662 (2017).

24. Cameron, K. et al. Recombinant Laminins Drive the Differentiation and Self-Organization of hESC-Derived Hepatocytes. Stem Cell Reports 5, 1-13 (2015).

25. Finoli, A., Schmelzer, E., Over, P., Nettleship, I. \& Gerlach, J. C. Open-porous hydroxyapatite scaffolds for three-dimensional culture of human adult liver cells. Biomed Res. Int. 2016, 1-7 (2016).

26. Celiz, A. D. et al. Discovery of a Novel Polymer for Human Pluripotent Stem Cell Expansion and Multilineage Differentiation. Adv. Mater. 27, 4006-4012 (2015).

27. Villarin, B. L. et al. Polymer Supported Directed Differentiation Reveals a Unique Gene Signature Predicting Stable Hepatocyte Performance. Adv. Healthc. Mater. (2015).

28. Steele, J. A. M. et al. Combinatorial scaffold morphologies for zonal articular cartilage engineering. Acta Biomater. 10, 2065-2075 (2014).

29. Chung, S. et al. Responsive poly ( $\gamma$-glutamic acid) fibres for biomedical applications. J. Mater. Chem. B 1, 1397 (2013).

30. Faulk, D. M., Johnson, S. A., Zhang, L. \& Badylak, S. F. Role of the extracellular matrix in whole organ engineering. J. Cell. Physiol. 229, 984-9 (2014).

31. Godoy, P. et al. Gene network activity in cultivated primary hepatocytes is highly similar to diseased mammalian liver tissue. Arch. Toxicol. 90, 1-17 (2016).

32. Blache, U., Stevens, M. M. \& Gentleman, E. Harnessing the secreted extracellular matrix to engineer tissues. Nature Biomedical Engineering 1-7 (2020).

33. Dokmanovic, M., Clarke, C. \& Marks, P. A. Histone Deacetylase Inhibitors: Overview and Perspectives. Mol. Cancer Res. 5, 981-989 (2007).

34. Yang, W. C. et al. Addition of Valproic Acid to CHO Cell Fed-Batch Cultures Improves Monoclonal Antibody Titers. Mol. Biotechnol. 1-8 (2013).

35. Xu, W. S., Parmigiani, R. B. \& Marks, P. Histone deacetylase inhibitors: molecular mechanisms of action. Oncogene 26, 5541-5552 (2007).

36. Kruh, J. Effects of sodium butyrate, a new pharmacological agent, on cells in culture. Mol. Cell. Biochem. 42, 65-82 (1982).

37. Martinez-Hernandez, A. \& Amenta, P. S. The hepatic extracellular matrix I. Components and distribution in normal liver. Virchows Arch. A Pathol. Anat. Histopathol. 423, 1-11 (1993).

38. Dunn, J. C., Yarmush, M. L., Koebe, H. G. \& Tompkins, R. G. Hepatocyte function and extracellular matrix geometry: long-term culture in a sandwich configuration. FASEB J. $\mathbf{3}$, 174-7 (1989).

39. Carlsson, R., Engvall, E., Freeman, A. \& Ruoslahti, E. Laminin and fibronectin in cell adhesion: enhanced adhesion of cells from regenerating liver to laminin. Proc. Natl. Acad. Sci. 78, 2403- 
2406 (1981).

40. Matsuzawa, A., Matsusaki, M. \& Akashi, M. Construction of three-dimensional liver tissue models by cell accumulation technique and maintaining their metabolic functions for longterm culture without medium change. J. Biomed. Mater. Res. A 1-11 (2014).

41. McCullen, S. D., Autefage, H., Callanan, A., Gentleman, E. \& Stevens, M. M. Anisotropic Fibrous Scaffolds for Articular Cartilage Regeneration. Tissue Eng. Part A 18, 2073-2083 (2012).

42. Sell, S. a. et al. The use of natural polymers in tissue engineering: A focus on electrospun extracellular matrix analogues. Polymers (Basel). 2, 522-553 (2010).

43. Su, W. T., Liu, Y. J. \& Huang, T. Y. Nanofibers promote HepG2 aggregate formation and cellular function. Genet. Mol. Res. 15, (2016).

44. Butcher, A. L., Offeddu, G. S. \& Oyen, M. L. Nanofibrous hydrogel composites as mechanically robust tissue engineering scaffolds. Trends Biotechnol. 32, 564-570 (2014).

45. Badylak, S. F. The extracellular matrix as a scaffold for tissue reconstruction. Semin. Cell Dev. Biol. 13, 377-383 (2002).

46. Egeblad, M., Rasch, M. G. \& Weaver, V. M. Dynamic interplay between the collagen scaffold and tumor evolution. Curr. Opin. Cell Biol. 22, 697-706 (2010).

47. Backliwal, G. et al. Valproic acid: A viable alternative to sodium butyrate for enhancing protein expression in mammalian cell cultures. Biotechnol. Bioeng. 101, 182-189 (2008).

48. Pfeifer, a M. et al. Simian virus 40 large tumor antigen-immortalized normal human liver epithelial cells express hepatocyte characteristics and metabolize chemical carcinogens. Proc. Natl. Acad. Sci. U. S. A. 90, 5123-5127 (1993).

49. Inomata, K., Oga, A., Kawauchi, S., Furuya, T. \& Sasaki, K. Global genomic changes induced by two-stage carcinogen exposure are precancerous alterations in non-transformed human liver epithelial THLE-3 cells. Int. J. Oncol. 27, 925-31 (2005).

50. Crapo, P. M., Gilbert, T. W. \& Badylak, S. F. An overview of tissue and whole organ decellularization processes. Biomaterials 32, 3233-3243 (2011).

51. Hay, D. C. et al. Efficient differentiation of hepatocytes from human embryonic stem cells exhibiting markers recapitulating liver development in vivo. Stem Cells 26, 894-902 (2008).

52. Takebe, T. et al. Generation of a vascularized and functional human liver from an iPSCderived organ bud transplant. Nat. Protoc. 9, 396-409 (2014).

53. Broutier, L. et al. Culture and establishment of self-renewing human and mouse adult liver and pancreas 3D organoids and their genetic manipulation. Nat. Protoc. 11, 1724-43 (2016).

54. Li, Q. et al. Proteomic analysis of naturally-sourced biological scaffolds. Biomaterials 75, 3746 (2016).

55. Xiang, J. et al. Decellularized spleen matrix for reengineering functional hepatic-like tissue 
based on bone marrow mesenchymal stem cells. Organogenesis 12, 128-142 (2016).

56. Gao, R. et al. Hepatocyte Culture in Autologous Decellularized Spleen Matrix. Organogenesis (2015).d

57. Faulk, D. M., Wildemann, J. D. \& Badylak, S. F. Decellularization and Cell Seeding of Whole Liver Biologic Scaffolds Composed of Extracellular Matrix. J. Clin. Exp. Hepatol. 5, 69-80 (2015).

58. Godoy, P. et al. Recent advances in 2D and 3D in vitro systems using primary hepatocytes, alternative hepatocyte sources and non-parenchymal liver cells and their use in investigating mechanisms of hepatotoxicity, cell signaling and ADME. Archives of Toxicology 87, (2013).

59. Chen, G. Y. \& Nuñez, G. Sterile inflammation: sensing and reacting to damage. Nat. Rev. Immunol. 10, 826-37 (2010).

60. He, M., Callanan, A., Lagaras, K., Steele, J. A. M. \& Stevens, M. M. Optimization of SDS exposure on preservation of ECM characteristics in whole organ decellularization of rat kidneys. J. Biomed. Mater. Res. Part B Appl. Biomater. 1-9 (2016). doi:10.1002/jbm.b.33668

61. Hotaling, N. a., Bharti, K., Kriel, H. \& Simon, C. G. DiameterJ: A validated open source nanofiber diameter measurement tool. Biomaterials 61, 327-338 (2015).

62. Lu, H., Hoshiba, T., Kawazoe, N. \& Chen, G. Comparison of decellularization techniques for preparation of extracellular matrix scaffolds derived from three-dimensional cell culture. $J$. Biomed. Mater. Res. A 100, 2507-16 (2012).

63. Oniscu, G. C. et al. In situ normothermic regional perfusion for controlled donation after circulatory death - The United Kingdom experience. Am. J. Transplant. 14, 2846-2854 (2014).

64. Papadopoulos, N. G. et al. An improved fluorescence assay for the determination of lymphocyte-mediated cytotoxicity using flow cytometry. J. Immunol. Methods 177, 101-11 (1994).

65. Grant, R., Hallett, J., Forbes, S., Hay, D. \& Callanan, A. Blended electrospinning with human liver extracellular matrix for engineering new hepatic microenvironments. Sci. Rep. 9, (2019).

66. Doumas, B. T., Watson, W. A. \& Biggs, H. G. Albumin standards and the measurement of serum albumin with bromcresol green. Clin. Chim. Acta 258, 21-30 (1997).

67. Dragan, A. I. et al. Characterization of PicoGreen Interaction with dsDNA and the Origin of Its Fluorescence Enhancement upon Binding. Biophys. J. 99, 3010-3019 (2010).

68. Livak, K. J. \& Schmittgen, T. D. Analysis of relative gene expression data using real-time quantitative PCR and the 2-ÄÄCT method. Methods 25, 402-408 (2001).

69. Callanan, A., Davis, N. F., McGloughlin, T. M. \& Walsh, M. T. Development of a rotational cellseeding system for tubularized extracellular matrix (ECM) scaffolds in vascular surgery. J. Biomed. Mater. Res. Part B Appl. Biomater. 102, 781-788 (2014). 


\section{Acknowledgements}

The authors wish to thank the donors and their families for their selfless sacrifice, who enabled this work to take place. We also thank the staff at NHS Organ Donation and Transplant, NHS Blood and Transplant and all surgical and medical staff involved for their support and assistance. The authors would like to thank Prof. Alistair Elfick for use of lab facilities (IBioE, University of Edinburgh) and Prof. Stuart Forbes for use of equipment (SCRM, University of Edinburgh). We would also like to thank Steve Mitchell (BioSEM) and Dr. David Kelly (COIL) for imaging assistance. This work is funded by an Engineering \& Physical Sciences Research Council [EPSRC] doctoral training partnership studentship, UK Regenerative Medicine Platform II [RMPII] grant MR/ L022974/1 and MRC computational and chemical biology of the stem cell niche grant (CCBN) MR/L012766/1.

\section{Author contributions statement}

R.G. conducted experiments, wrote the main manuscript text and prepared all figures. J.H. and S.F. provided access to liver tissue and assisted with tissue retrieval. D.H. reviewed results and assisted with experimental design. A.C. supervised the project and provided all experimental resources. All authors discussed the results and edited the manuscript. 


\section{Figures}

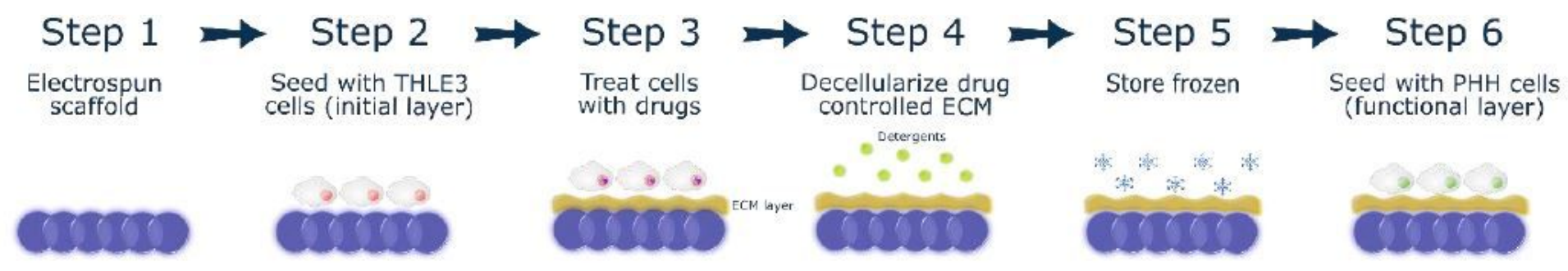

Figure 1

Method schematic

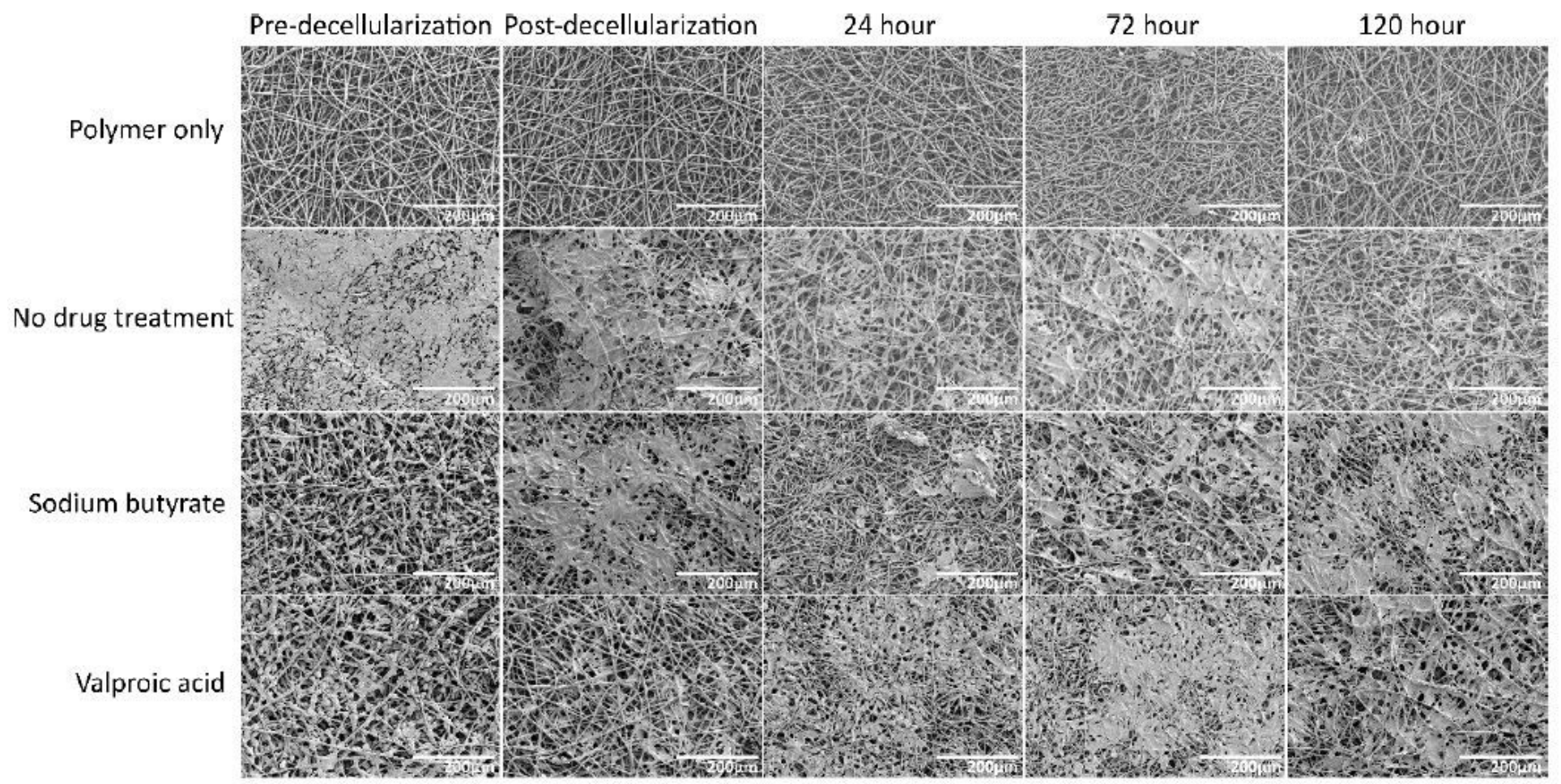

\section{Figure 2}

SEM of Scaffold-ECM constructs and functional cell layers Scanning electron microscopy images of the decellularized scaffold-ECM constructs and functional cell layers at 24, 72 and 120 hours culture. Topographical differences are clearly evident on decellularized constructs. 500x magnification. 


\section{Picogreen of decellularized constructs \\ $95 \% \mathrm{Cl}$ for the Mean}

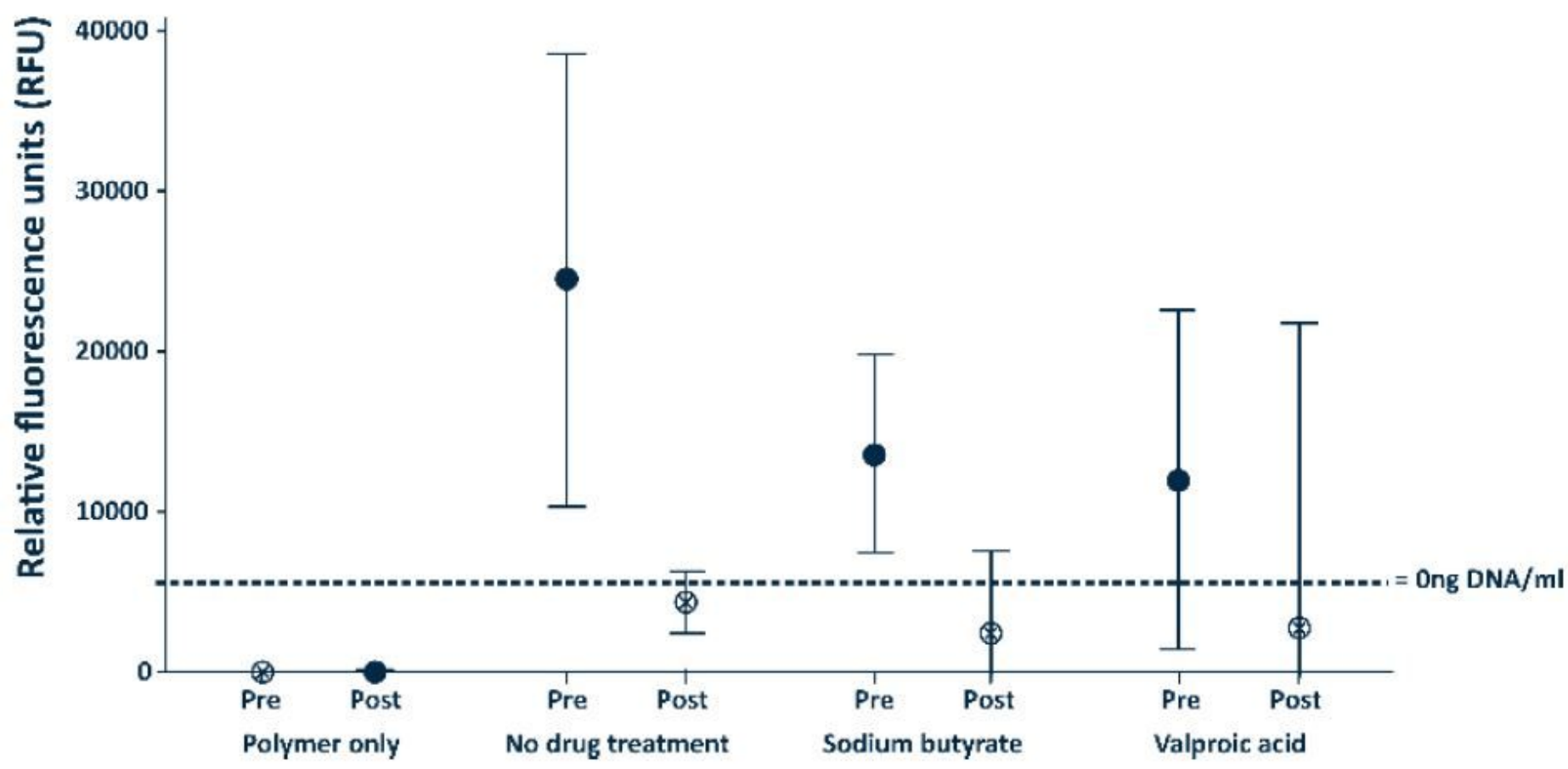

Figure 3

Decellularization of initial layer Decellularization was confirmed using the Quant-IT ${ }^{\mathrm{TM}}$ Picogreen ${ }^{\circledR}$ dsDNA assay and scanning electron microscopy (Fig. 2). 


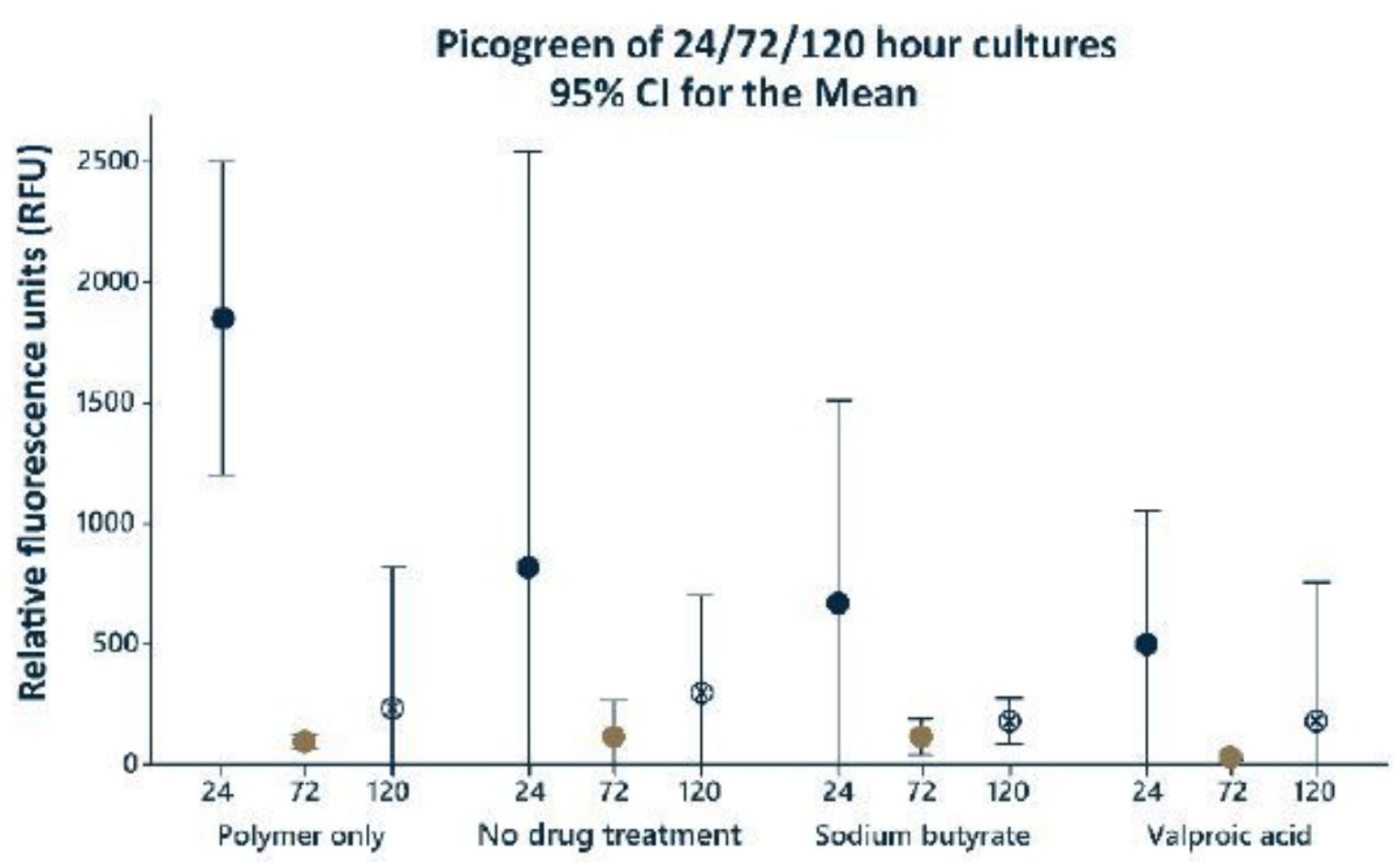

MTT assay

$95 \% \mathrm{Cl}$ for the Mean

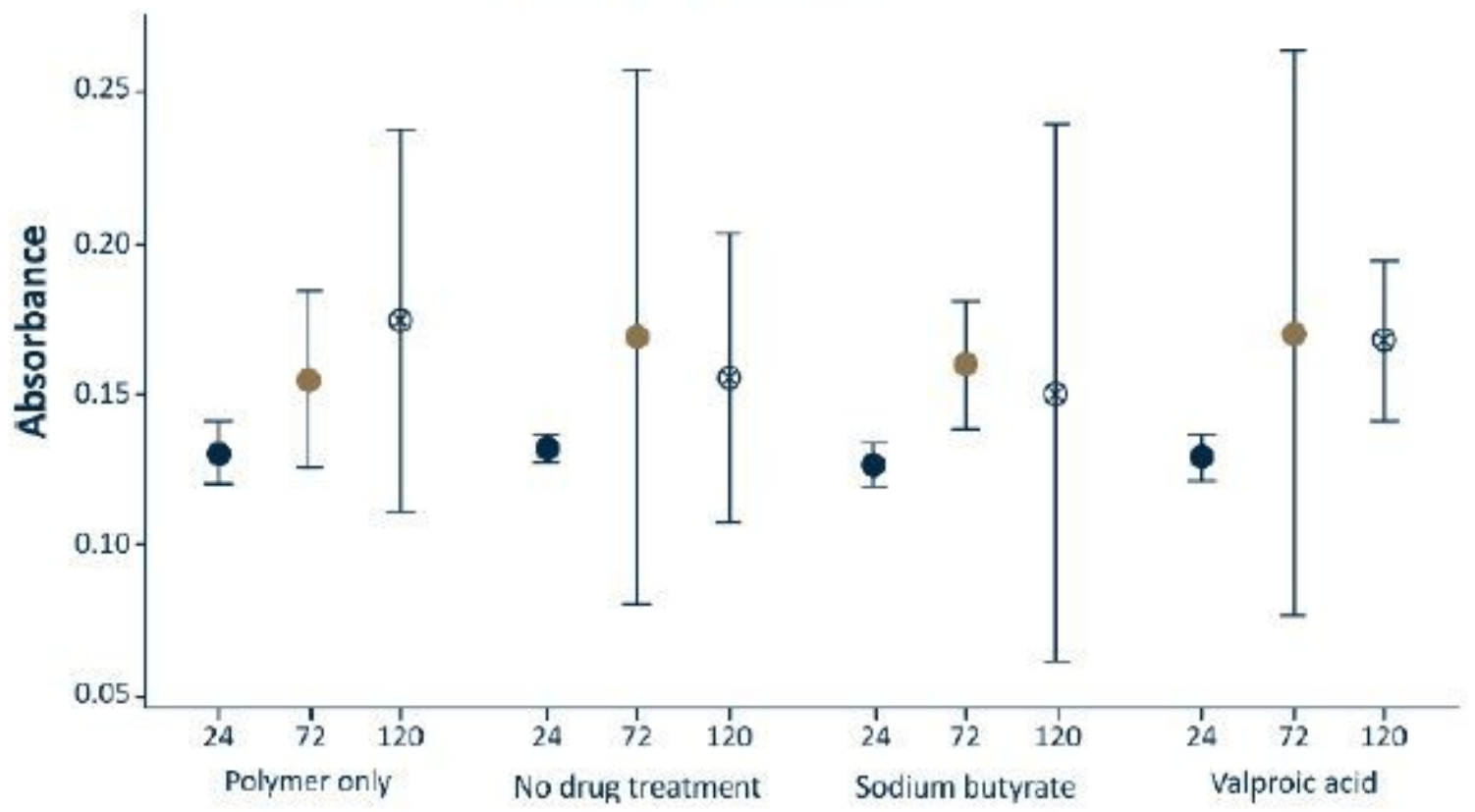

Figure 4

Seeding efficiency/viability on scaffolds Cell adherence was assessed by Quant-IT ${ }^{\mathrm{TM}}$ Picogreen ${ }^{\circledR} \mathrm{dsDNA}$ assay and metabolic viability confirmed by MTT absorbance assay One-way ANOVA with Tukey post hoc testing. ${ }^{*}=p<0.05 * \star=p<0.01$. Error bars represent SD. 


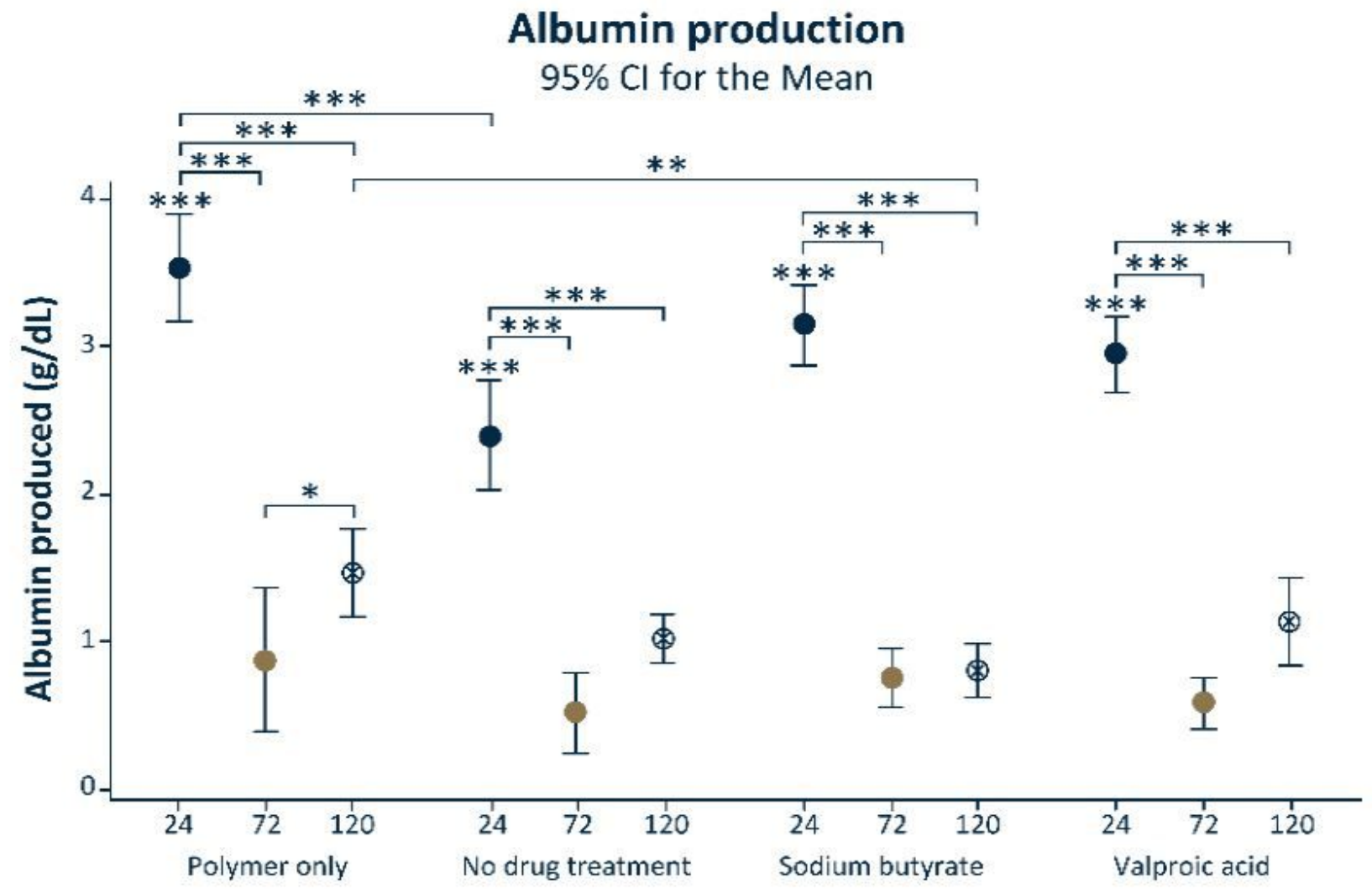

Figure 5

Albumin production on scaffolds Cell function was assayed by checking for albumin protein production. One-way ANOVA with Tukey post hoc testing. ${ }^{*}=p<0.05 * \star=p<0.01$. Error bars represent SD. 


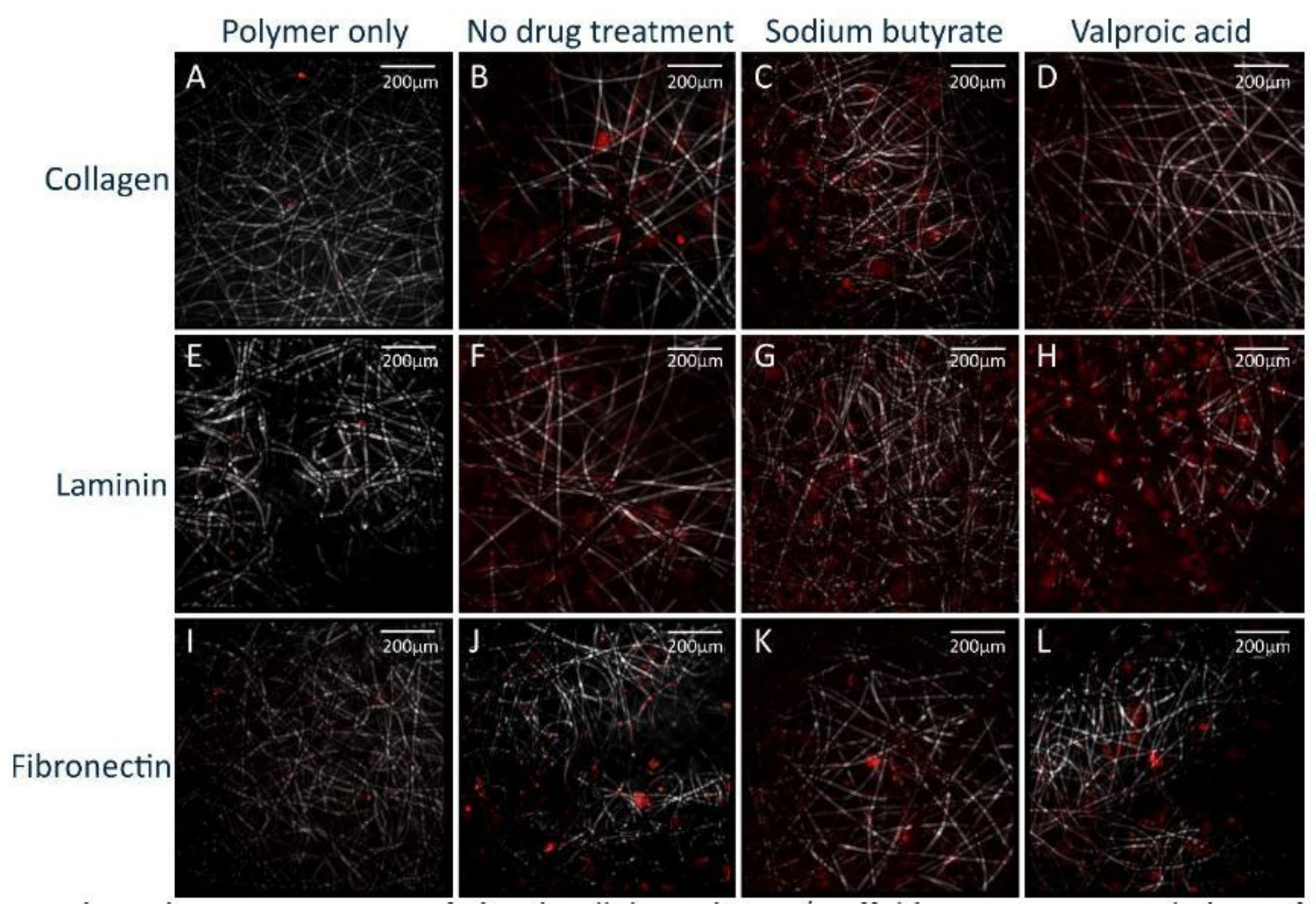

Figure 6

Immunohistochemical investigation Immunohistochemistry staining of the decellularized ECM/scaffold constructs revealed significant differences in ECM components. Stains were performed for Collagen I $(A, B, C, D)$, Laminin $(E, F, G, H)$ and Fibronectin $(I, J, K, L)$, post processed using Image. 


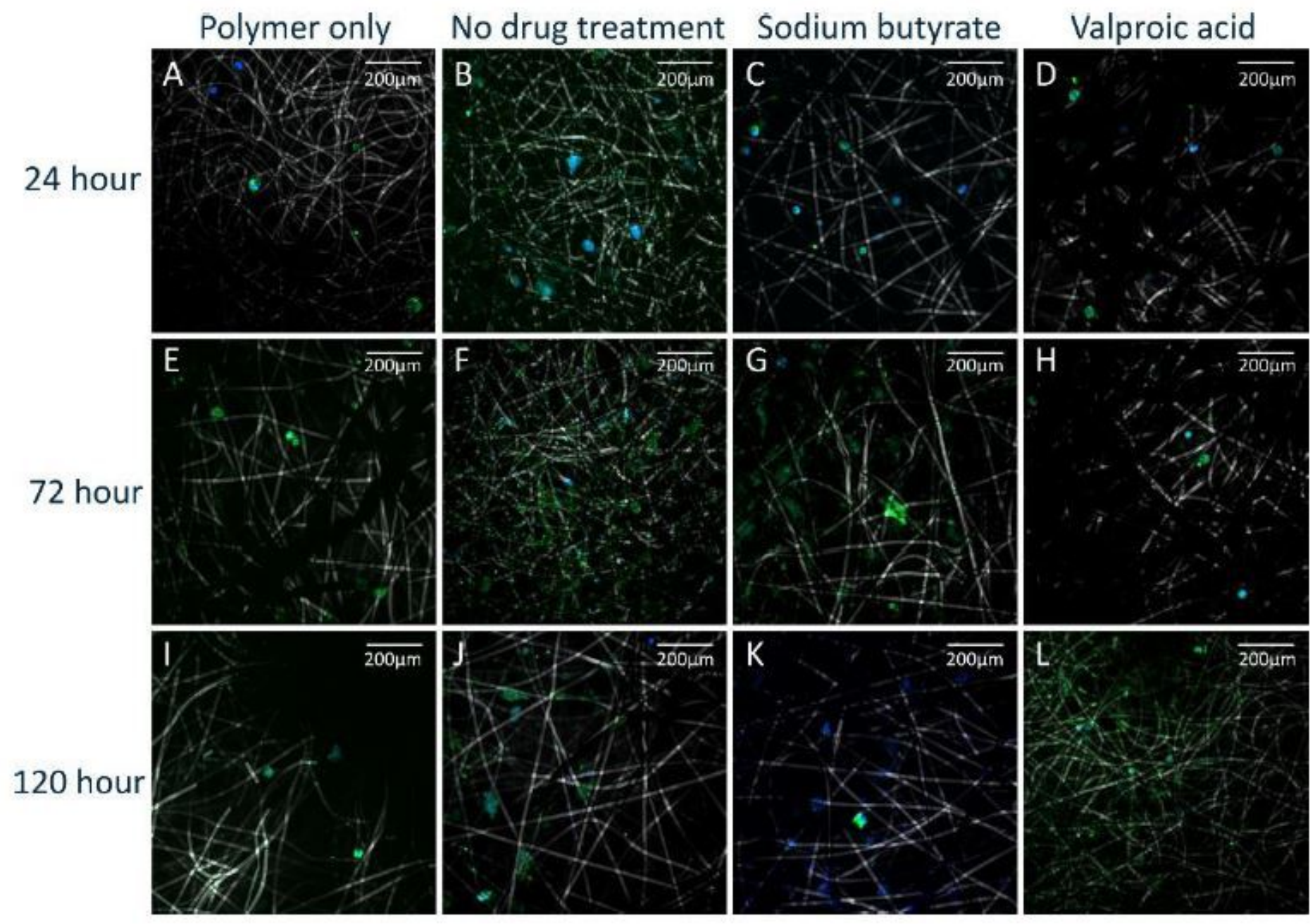

Figure 7

Cell imaging Dapi and phalloidin staining of cell/scaffold constructs revealed cells present at each timepoint, post processed using ImageJ. 
A.

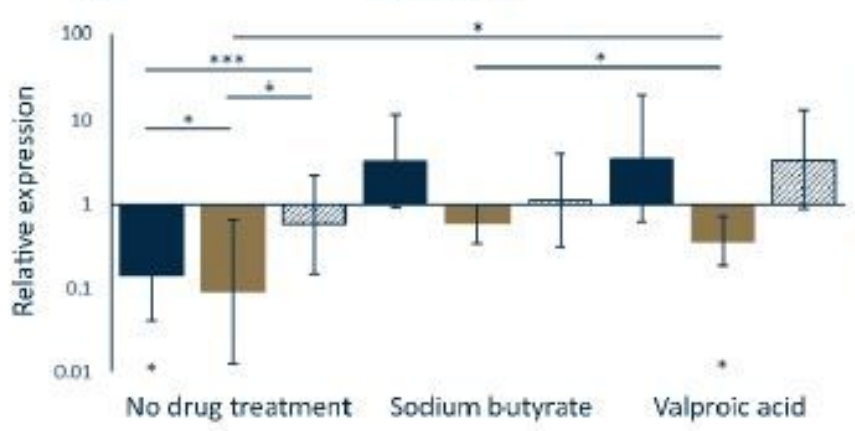

B.

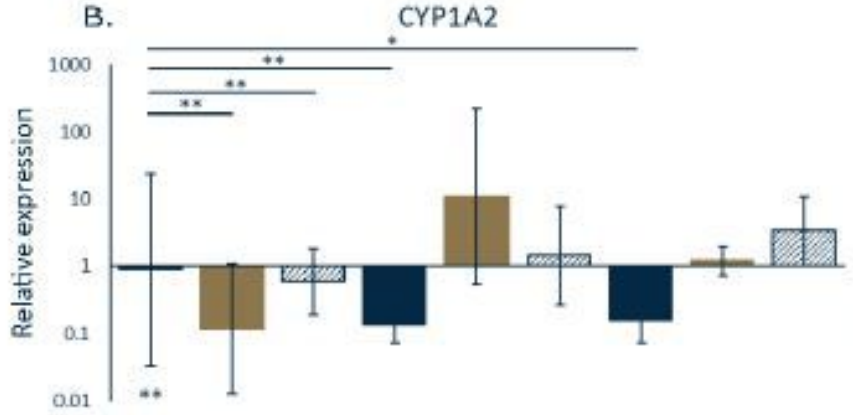

No drug treatment Sodium butyrate Valproic acid

c.

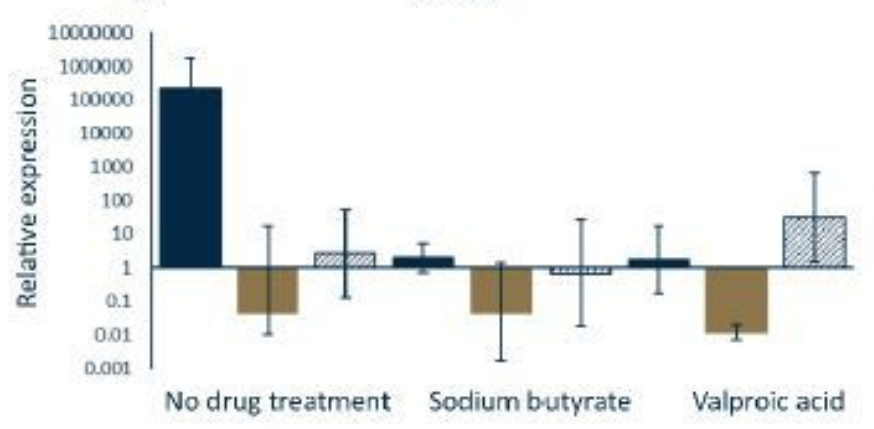

D.

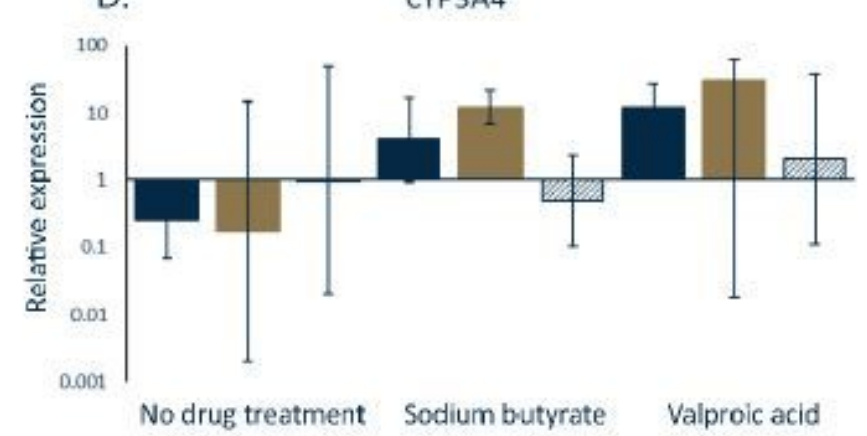

E.

COL1A1

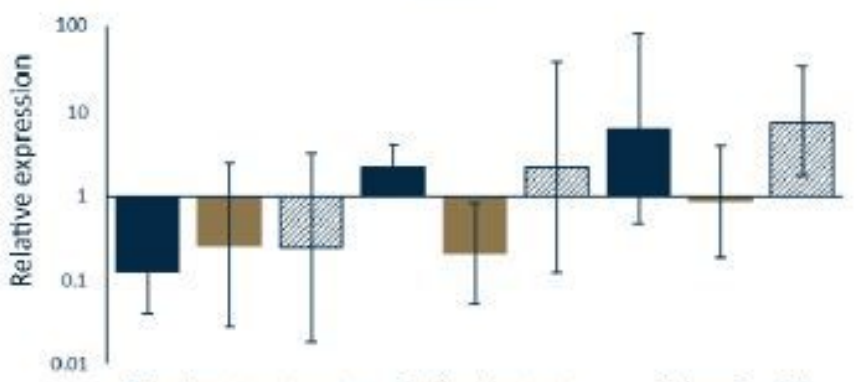

No drug treatment Sodium butyrate Valproic acid

F. COL4A1

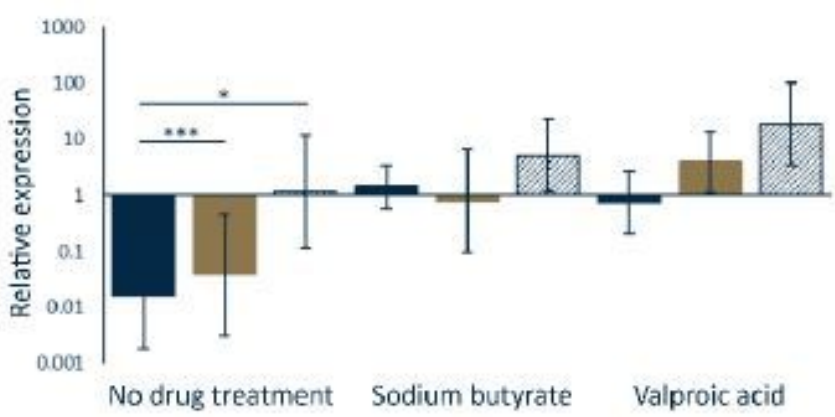

G.

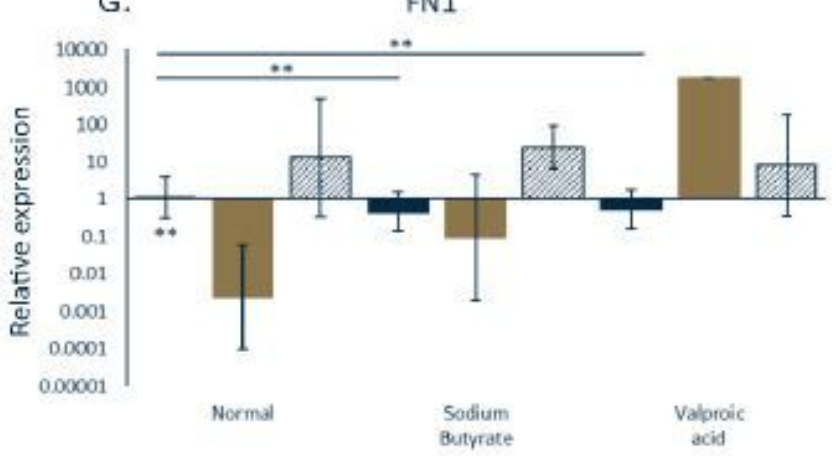

$24 \mathrm{hr}$

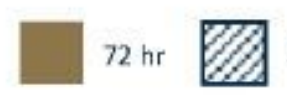

$120 \mathrm{hr}$

\section{Figure 8}

Q-PCR analysis of functional cell layer Quantitative analysis of gene expression was undertaken on the functional cell layer 24, 72 and 120 hours culture, compared to that of the polymer only condition at each timepoint. mRNA levels of Albumin (A), CYP1A2 (B), CYP2B6 (C), CYP3A4 (D), Collagen I (E) Collagen IV $(\mathrm{F})$, and Fibronectin $(\mathrm{G})$ are represented as fold difference relative to tissue culture plastic controls and 
relative to the housekeeping gene GAPDH. One-way ANOVA with Games-Howell post hoc testing and minimum $n=4 . *=p<0.05 * \star=p<0.01$. Error bars represent SD. 